Faculty of Engineering - University of Porto

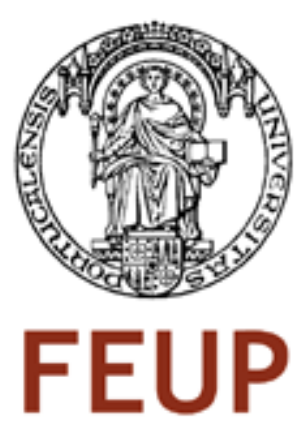

\title{
Development of a System for Automatic Detection of Air Embolism Using a Precordial Doppler
}

\author{
Ana Rita da Costa Tedim
}

FINAL VERSION

Dissertation developed under the Integrated Master in Bioengineering

Field of Biomedical Engineering

Supervisor: Dr. Ana Castro

Co-supervisor: Prof. Dr. Pedro Amorim

$22^{\text {nd }}$ October 2013 
(c) Ana Rita da Costa Tedim, 2013 


\section{Abstract}

Venous air embolism (VAE) is the air bubble accumulation in the right side of the heart, as result of pressure gradients between the heart and the incisional area, that may cause problems like cerebral ischemia or cardiovascular collapse. Monitoring protocols are implemented as a way to prevent/detect VAE, and include the use of a precordial Doppler. The precordial Doppler allows a real-time monitoring of the heart sound. Changes in heart sound are characteristic of VAE, and the anesthesiologist has to pay attention to this event, what is not always possible since he is responsible for different tasks in the operating room. To overcome this, it is important to find other robust methods of VAE detection. This work aims to study different features of heart sound that may provide useful information on VAE episodes.

A clinical protocol was designed, and after approval 6 patients were enrolled in this study. Doppler heart sound (DHS) was collected at baseline and following infusions of saline with 4 distinct volumes $(1 \mathrm{ml}, 5 \mathrm{ml}, 8 \mathrm{ml}$ and $10 \mathrm{ml}$ ) and two infusion rates (slow and fast), were given by central and peripheric catheters. Following signal pre-processing the envelope of each signal was extracted. Five features were implemented and evaluated: frequency corresponding to $95 \%$ of Welch periodogram power (f95), frequency corresponding to $50 \%$ of Welch periodogram power (f50), frequency corresponding to maximum power spectral density (fm), entropy (E) and frequency corresponding to maximum energy of a wavelet transform (freqwav). Relation between extracted features and saline infusions of a wavelet were studied and compared to baseline values. A Graphical User Interface (GUI) with a database of Doppler heart sounds and annotations was also developed, allowing for the offline analysis and features extraction of the DHS.

After identification of peaks corresponding individual heart sounds, features were extracted for each time injection annotated by the researcher. Although features present $a$ high variability, E presents a better performance showing an increase in response to saline injections. The feature with worse results was fm since almost no difference was observed during turbulence episodes. Higher infusion volumes administered by central catheter, resulted in more pronounced responses of the evaluated features. This was expected because the infusions via central catheter enter directly in the heart, where the Doppler probe is placed (externally), so the turbulence information is not lost. 
Future work will include the increase of the number of acquisitions to improve the database created, the acquisition and study of heart sounds when VAE events occur to evaluate the robustness of the features in detecting air in the circulation, and the adaptation of the GUI for online analysis. This would allow to implement an advisory system that could aid the anesthesiologist detect VAE episodes more rapidly. 


\section{Resumo}

Embolia Gasosa traduz-se na acumulação de bolhas de ar no lado direito do coração, como resultado da existência de gradientes de pressão entre o coração e a área de incisão. Este evento pode causar vários problemas de saúde, nomeadamente isquemia cerebral ou colapsos cardiovasculares. Como forma de prevenir/detetar embolias gasosas, são implementados protocolos de monitorização que incluem o uso do Doppler precordial, uma vez que este permite ouvir o som cardíaco em tempo real. Quando ocorre um episódio de embolia gasosa, surgem alterações no som cardíaco, as quais devem ser detetadas pelo anestesiologista, o que nem sempre é possível pois este é também responsável por outras tarefas dentro do bloco operatório, aumentando desta forma o tempo entre o episódio e a deteção do problema. Torna-se por isso imperativo encontrar outro método de deteção de embolias gasosas mais eficaz. Assim, este trabalho pretende estudar diferentes características do som de Doppler cardíaco com o objectivo de se encontrar informação útil acerca dos eventos de embolia gasosa.

Foi então elaborado o primeiro estudo em humanos, que após submetido e aceite permitiu que se efetuassem aquisições de som cardíaco em 6 pacientes: foi colhido som cardíaco com características basais e após injeções de soro fisiológico com 4 volumes distintos $(1 \mathrm{ml}, 5 \mathrm{ml}$, $8 \mathrm{ml}$ e $10 \mathrm{ml}$ ) e duas velocidades (uma mais lenta e outra mais rápida) pelos cateteres central e periférico. Após o pré processamento, foram extraídos os envelopes das respetivas aquisições. 5 características foram implementadas e avaliadas: $\mathrm{f95}, \mathrm{f50}, \mathrm{fm}, \mathrm{E}$ e freqwav e as tendências entre os resultados obtidos e volumes de infusão foram também avaliados. Foi também criada uma interface gráfica contendo uma base de dados de som cardíaco e anotações, permitindo fazer uma análise off-line e extrair as características avaliadas.

Após identificação dos picos correspondentes a batimentos cardíacos individuais, características foram extraídas para cada tempo de injecção e anotadas pelo investigador. Apesar de os resultados apresentarem elevada variabilidade, foi possível verificar que $\mathrm{E}$ apresenta uma melhor performance mostrando um aumento em resposta às injeções. A característica com piores resultados foi $\mathrm{fm}$ uma vez que quase não se alterou durante os episódios de turbulência do som. As administrações de elevados volumes via cateter central aumentam a turbulência do som, portanto as características avaliadas apresentaram também 
uma taxa de aumento mais elevada como esperado, uma vez que as infusões por esta via são administradas directamente no coração, sobre o qual está colocada a sonda Doppler (externamente). Assim, não se perdeu informação relativa à turbulência para estes casos.

Trabalho futuro inclui o aumento do número de aquisições para melhorar a base de dados criada, a aquisição e estudo de som cardíaco quando episódios de embolia gasosa ocorrerem para avaliação da robustez das características, e adaptação da interface para análise em tempo real. Isto permitirá implementar um sistema de deteção que alertará o anestesiologista para a ocorrência de embolias gasosas mais rapidamente. 


\section{Acknowledgments}

To my parents Manuel and Manuela who made everything to give me education and love.

To my brothers João and Tiago and my sister-in-law Claudia, for teaching me the value of a good friendship.

To my best friends Helena e Gonçalo, who gave me strength to overcome the difficulties.

To my nephew João Pedro, that only with his smile can turn my worst days in better days.

To Luis, for all the support, for being my pillar and always believe in my capacities.

To my supervisor Ana Castro and co-supervisor Pedro Amorim, who always praised my work and help me no matter what my doubts were.

Your purpose in life is to find your purpose and give your whole heart and soul to it.

Gautama Buddha 



\section{Index}

Chapter1......................................................................... 1

Introduction........................................................................... 1

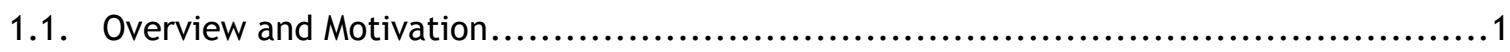

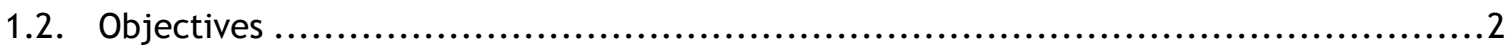

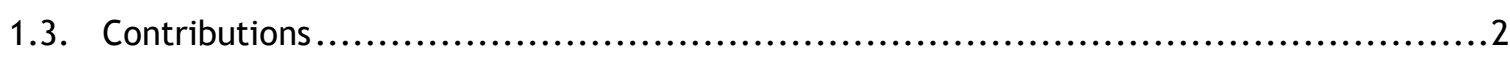

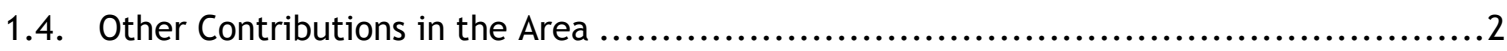

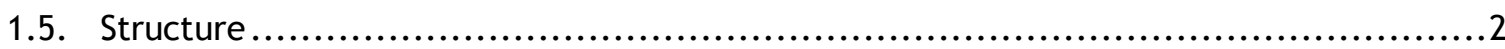

Chapter 2............................................................................. 4

Venous Air Embolism .............................................................. 4

2.1. Physiology of the Heart .............................................................. 4

2.2. Clinical Presentation.......................................Erro! Marcador não definido.

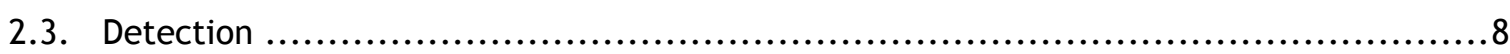

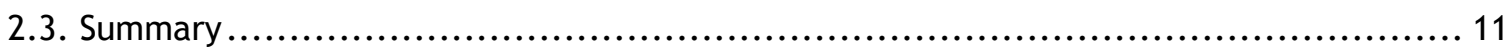

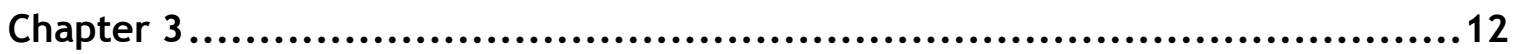

State of the Art.............................................................. 12

3.1. Doppler Heart Sound Analysis ................................................... 12

3.2. Real-Time Doppler Heart Sound Analysis........................................... 17

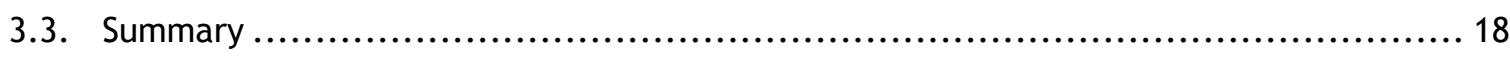

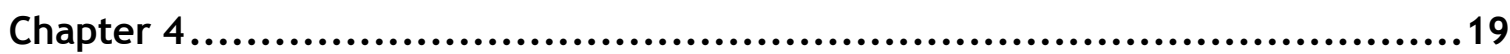

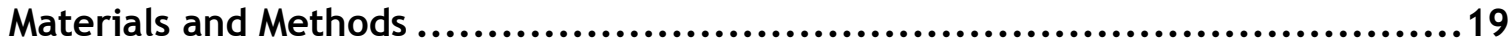

4.1. Clinical Protocol and Data Acquisition ................................................. 19

4.2. Heart Sound Segmentation ........................................................... 20

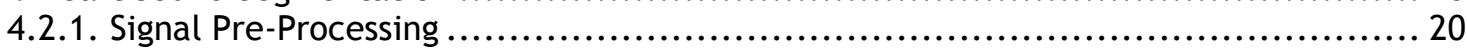

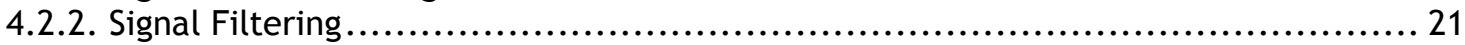

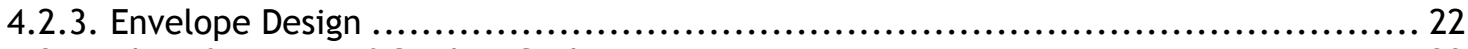

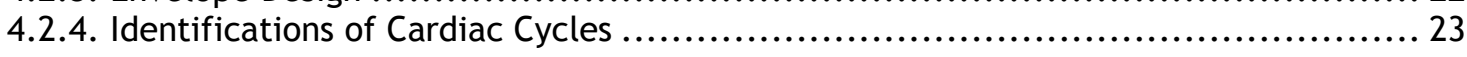

4.3. Doppler Heart Sound Features .......................................................... 23

4.3.1 Maximum Peak Frequency, Frequency at $95 \%$ and at 50\% from Welch Periodogram.... 24

4.3.2 Maximum Frequency from Continuous Wavelet Transform (CWT) ..................... 24

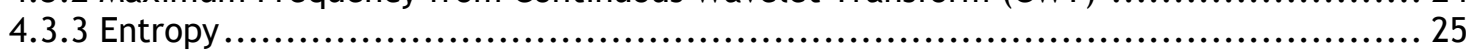

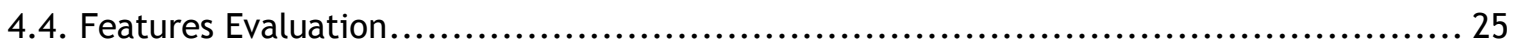




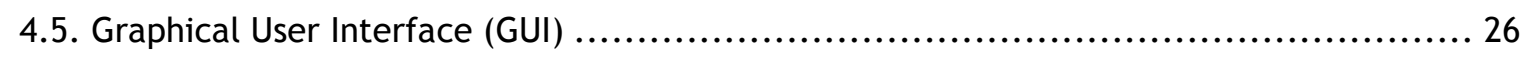

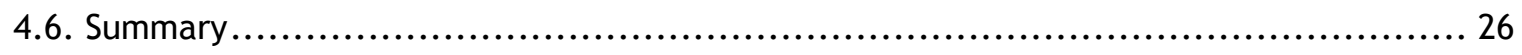

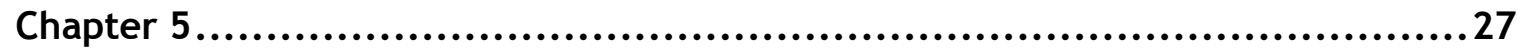

Results and Discussion ...................................................... 27

5.1. Data Collection and Pre-Processing................................................. 27

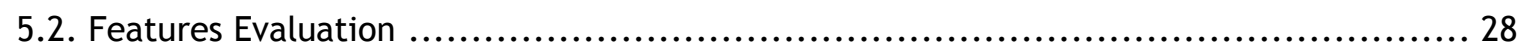

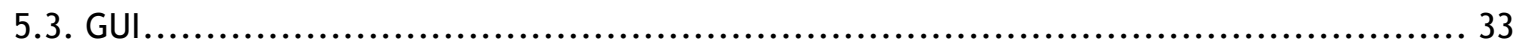

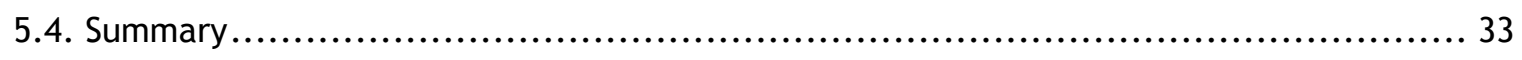

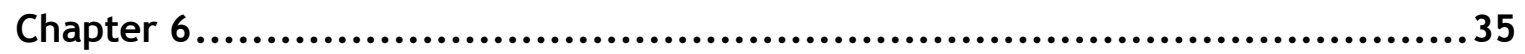

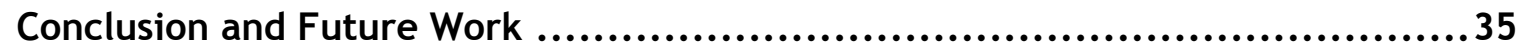

APPENDIX I ............................................................... 40

APPENDIX II.............................................................. 42

APPENDIX III .........................................................................44

APPENDIX IV.............................................................. 46

APPENDIX V ..................................................................47

APPENDIX VI..................................................................49

APPENDIX VII ................................................................. 53 


\section{Figures List}

Figure 1 - Structure of the heart, and course of blood flow (adapted from [7]). ..............

Figure 2 - Pressure gradients of different parts of the body (adapted from [7]).............6

Figure 3 - Adverse sequels from air embolism are dependent principally on the volume of air, as well as the rate of entrainment. Higher volumes of air have substantial effects on the cardiovascular, pulmonary, and cerebral organ systems. $\mathrm{ETCO}_{2}$ : endtidal carbon dioxide; $\mathrm{ETN}_{2}$ : end-tidal nitrogen (adapted from [4]).

Figure 4 - Doppler heart sound signal and signal envelope obtained by low pass filtering. The local minima of envelope divides the signal into cardiac cycles (adapted from [16]).

Figure 5 - DHS signal containing its WT at different scales $(j=1$ to 3 ). The embolic heartbeat after $0,02 \mathrm{ml}$ of air infusion (marked by an arrow) was confirmed by an anesthesiologist after listening to the Doppler heart sound signal (adapted from [16]).

Figure 6 - Normalized power of individual heartbeats after WT of DHS. The increase of power (for $\mathrm{j}=1$ and 2 ) identifies the embolic heartbeat above a threshold level that is two times the mean power level of the basal signal (adapted from [16]).

Figure 7 - Correlation between CEP and the volume of injected air at two different $j$ values: (a) $j=1$ and (b) $j=2$; with respective mean and standard deviation of 12 incidences of air injections obtained in four dogs. Figures 7(c) and 7(d) represents the linear regression in log-log scale of (a) and (b) and Figures 7(e) and 7(f) are the log-log plot of the normalized CEP versus the volume of injected air at $j=1$ and $j=2$, respectively, for average of 3 air injections in dog 3 (adapted from [16].

Figure 8 - Correlation and sensitivity of WT and Fmax and HF power (adapted from [16])... 16

Figure 9 - MSA of DHS and WT at $j=1$. The embolic heartbeat is detected by the MSA signal crossing the threshold level in the WT (adapted from [16]...................... 16

Figure 10 - Graphical interface of real-time monitor (adapted from [24]).................. 17

Figure 11 - Relation between the cumulative embolic air volume and the infusion time of $9.60 \mathrm{ml}$ air for $\operatorname{dog} \mathrm{A}$. The time of air infusion during the first 300 seconds (adapted

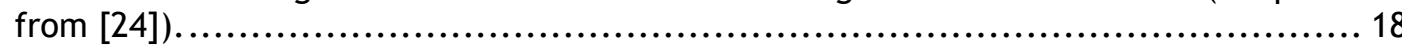

Figure 12 - Precordial Doppler from Hadeco, model Smartdop 45.......................... 19

Figure 13 - Filtered signal after the application of Savitzky-Golay filter with different frame sizes $(21,51$ and 201 , respectively). ........................................ 21

Figure 14 - Original signal and filtered signal using Butterworth and Savitzky-Golay

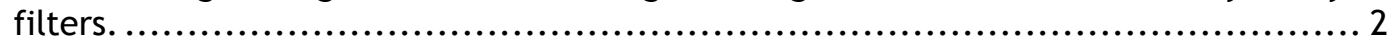


Figure 15 - Result of the application of findpeaks function with the parameter "minimum peak distance.

Figure 16 - Correlation between the two frames. ..................................... 23

Figure 17 - Signal and constituent wavelets of different scales and positions................ 24

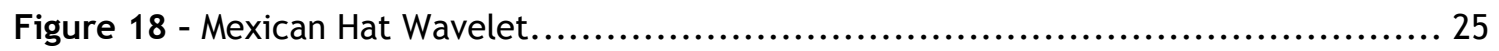

Figure 19 - Interface created to analyze the Doppler heart sound and present the results of the implemented methods. ...................................................... 26

Figure 20 - Relation between the infusion volume and the ratio of increase (\%) of f95 for A) slow and fast rates of saline infusion via central catheter; B) slow and fast rates of saline infusion via periferic catheter; C) slow infusion of saline via central and periferic catheter; D) fast infusion of saline via central and periferic catheter.

Figure 21 - Relation between the infusion volume and the ratio of increase (\%) of f50 for A) slow and fast velocities of saline infusion via central catheter; B) slow and fast velocities of saline infusion via periferic catheter; C) slow infusion of saline via central and periferic catheter; D) fast infusion of saline via central and periferic catheter.

Figure 22 - Relation between the infusion volume and the rate of increase (\%) of fm for A) slow and fast velocities of saline infusion via central catheter; B) slow and fast velocities of saline infusion via periferic catheter; $C$ ) slow infusion of saline via central and periferic catheter; D) fast infusion of saline via central and periferic catheter.

Figure 23 - Relation between the infusion volume and the rate of increase (\%) of $E$ for A) slow and fast velocities of saline infusion via central catheter; B) slow and fast velocities of saline infusion via periferic catheter; $C$ ) slow infusion of saline via central and periferic catheter; D) fast infusion of saline via central and periferic catheter.

Figure 24 - Relation between the infusion volume and the rate of increase (\%) of freqwav for A) slow and fast velocities of saline infusion via central catheter; B) slow and fast velocities of saline infusion via periferic catheter; C) slow infusion of saline via central and periferic catheter; D) fast infusion of saline via central and periferic catheter.

Figure 25 - Graphical Interface created and respective functions....

Figure 26. - The right atrial catheter positioned at the correct location to aspirate air. Electrocardiographic complexes at various intracardiac locations [3].

Figure 27 - Representation of the induction total volume $(\mathrm{ml} / \mathrm{kg})$ and the final infusion rate $(\mathrm{mg} / \mathrm{kg} / \mathrm{min})$, and corresponding linear regression.

Figure 28 - Doppler pré - cordial da Hadeco, modelo Smartdop $45^{\circ}$. 


\section{Tables List}

Table 1 - Surgical Procedures associated with VAE and respective rate of incidence (adapted from [4]). .................................................................

Table 2 - Comparison of methods of detection of VAE (adapted from [14]). $\mathrm{ET}_{\mathrm{CO}}=$ EndTidal Carbon Dioxide Gas; $\mathrm{ET}_{\mathrm{N} 2}=$ End-Tidal Nitrogen Gas; $\mathrm{N}_{2} \mathrm{O}=$ Nitrous oxide; $\mathrm{PA}=$ Pulmonary Artery; $\mathrm{TCD}=$ Transcranial Doppler; TEE $=$ Transesophageal Echo.

Table 3 - Preventive measures, patient monitoring and therapeutic management of VAE (adapted from [4]). End-tidal carbon dioxide $\left(\mathrm{EtCO}_{2}\right)$; end-tidal nitrogen( $\left(\mathrm{EtN}_{2}\right)$; nitrous oxide $\left(\mathrm{N}_{2} \mathrm{O}\right)$.

Table 4 - Mean and standard deviation of variables for each approach. Ce's for the patient 1, 4 and 10 were not recorded once all the time of anesteshia induction was minor than the chosen ( 5 minutes after de 2 nd bolus).

Table 5 - Mean of the five sound features' ratio evaluated, for each infusion via, velocity and volume. Mean_Mf95=mean of maximum frequency at $95 \%$ of Welch periodogram integral; Mean_Mf95=mean of maximum frequency at 50\% of Welch periodogram integral; Mean_Mfm=mean of maximum of maximum frequency of Welch periodogram; Mean_ME=mean of maximum Entropy; Mean_Mfreqwav=mean of maximum of maximum frequency using the continuous wavelet. 


\title{
Abbreviations and Symbols
}

\author{
A-V Atrium - Ventricle \\ $\mathrm{CO}_{2} \quad$ Carbon Dioxide \\ DHS Doppler Heart Sound \\ E Entropy \\ EEG Electroencephalogram \\ EHS Embolic Heart Sound \\ $\mathrm{EtCO}_{2} \quad$ End-Tidal Carbon Dioxide \\ $\mathrm{EtN}_{2} \quad$ End-Tidal Nitrogen \\ Fm Frequency corresponding to Maximum Power Spectral Density \\ Fmax Maximum Frequency \\ Freqwav Frequency corresponding to Maximum energy of a wavelet transform \\ F50 Frequency corresponding to $50 \%$ of Welch periodogram area \\ F95 Frequency corresponding to $95 \%$ of Welch periodogram area \\ GUI Graphical User Interface \\ HF High Frequency \\ NS Normal Saline \\ PA Arterial Pressure \\ PSD Power Spectral Density \\ RAC Right Arterial Catheter \\ TCD Transcranial Doppler \\ TEE Transesophageal Doppler \\ TIVA Total Intravenous Anesthesia \\ VAE Venous Air Embolism \\ WT Wavelet Transform
}




\section{Chapter1}

\section{Introduction}

\subsection{Overview and Motivation}

VAE is a serious complication that may occur during neurosurgical procedures [1]. It is the result of air bubble accumulation in the heart, causing over distension of the right side, and when not detected in time, causes many health problems like cyanosis, stroke, obstruction of pulmonary blood flow, or cardiovascular collapse [2, 3].

The accumulation of air bubbles is caused by the existence of pressure gradients between the right side of the heart and the incisional area, and it is more frequent for the sitting position (incidence of $25 \%$ ), but may also occur in the prone, supine or lateral positions (incidence ranging between 15\% and 25\%) [2].

Several studies indicate that systemic embolization into the cerebral, pulmonary, and coronary circulations may be catastrophic $[1,4]$.

To detect and prevent these problems, monitoring protocols are implemented, including a precordial ultrasonic Doppler probe, the insertion of a right atrium line for air aspiration, and the institution of high flow oxygen (see Appendix I for more detailed information) [2]. The Doppler probe allows a real-time monitoring of the heart sound [5]. Changes in heart tones, usually referred to as "mill-wheel murmurs" are characteristic of VAE and the anesthesiologist has an important role in the detection of these characteristic sounds, and subsequent intervention [2].

At this point, detecting VAE relies on the continuous attention of the anesthesiologist throughout surgical procedures to cardiovascular changes, and the Doppler sound beat-tobeat. Since the anesthesiologist needs to focus his attention on other tasks, detection of VAE may be disregarded; especially with the occurrence of false positives.

In this context, it is imperative to assist the decision of the anesthesiologist by studying and developing other robust methods of VAE detection. The study of the Doppler heart sound (DHS) at different levels may provide valuable information for VAE episodes detection. 


\subsection{Objectives}

Familiarize with concepts in neuroanesthesiology, such as VAE, and precordial Doppler, and also to explore signal processing techniques proposed in the literature for Doppler heart sound (DHS) analysis.

Study DHS changes and propose different methods for its processing and features extraction.

Evaluate the proposed metrics in response to different administered volumes and administration rates, of intravenous saline injections.

Develop a system for offline analysis of the DHS, with features extraction and visualization.

\subsection{Contributions}

Design and submission for institutional approval, of the first clinical study in humans, to study signal processing techniques in the detection of turbulence episodes through DHS analysis.

Creation of a database of Doppler sounds, standardized, and with annotations of the saline injections timing with correspondent volumes and administration rate.

Analysis of the proposed methods in the literature, and analysis of new metrics for the evaluation of Doppler sound characteristics (normal flow/turbulent flow).

Propose DHS characteristics that allow a better detection of turbulence episodes.

\subsection{Other Contributions in the Area}

The interest in the neuroanesthesiology field has been always present in this work, leading to research questions not directly linked to the dissertation focus, which naturally came up during the work development.

Seeking to going deeper in these questions, a different study was developed, which consisted in the creation of a new scheme for manual infusion of propofol, allowing individualization of doses required for anesthesia induction and adequacy of the initial maintenance rate. Initial results of this work will be published in the proceedings of the 41st Annual Meeting of the Society for Neuroscience in Anesthesiology and Critical Care (SNACC), to be presented October 10th, 2013. More information about this work is presented in Appendix II.

\subsection{Structure}

This dissertation is divided in 6 chapters. In the first, the motivation and objectives of the work are presented. Also, the contributions of the dissertation are listed. 
The second chapter is focused on the description of the research question, namely the clinical presentation and current forms of VAE detection, as well as the studies made so far to validate the efficiency of the detection devices used in clinical practice.

The third chapter presents the state of the art on DHS signal processing.

In the fourth chapter the methodology proposed in this work is introduced, and in the fifth chapter obtained results and its discussion are presented.

The sixth chapter presents the main conclusions of this dissertation and refers to possible future work. 


\section{Chapter 2}

\section{Venous Air Embolism}

This chapter begins with a brief explanation of the physiology of the heart, and then focuses on Venous Air Embolism, namely its clinical presentation and the available methods to detect this event.

\subsection{Physiology of the Heart}

The heart is composed of three major types of cardiac muscle: atrium muscle, ventricular muscle, and conductive muscle fibers. The duration of contraction of atrial and ventricular types of muscle is much longer that of skeletal muscle [6].

The beating of the heart is controlled by excitatory and conductive fibers that receive rhythmical electrical discharge in the form of action potentials. As can be seen in Figure 1, the heart is composed by 4 chambers, 2 atrium and 2 ventricles [6].

The cardiac cycle is expressed by the cardiac events that occur between the beginning of one heartbeat and the beginning of the next. Each cycle starts with the generation of action potential in the sinus node, located in superior wall of the right atrium. The potential travels then through both atria and Atria-Ventricle $(A-V)$ bundle into the ventricles. The arrangement of this conduction system allows a delay of more than 0,1 seconds during the passage of cardiac impulses from atria to ventricles, which allows the contraction of the atria first, and then ventricles. Thus, atria act as primary pumps for the ventricles, and the ventricles provide the power to move the blood through the body's vascular system. The periods of relaxation, when the heart fills with blood are diastoles, and the periods of contraction are systoles [7]. 


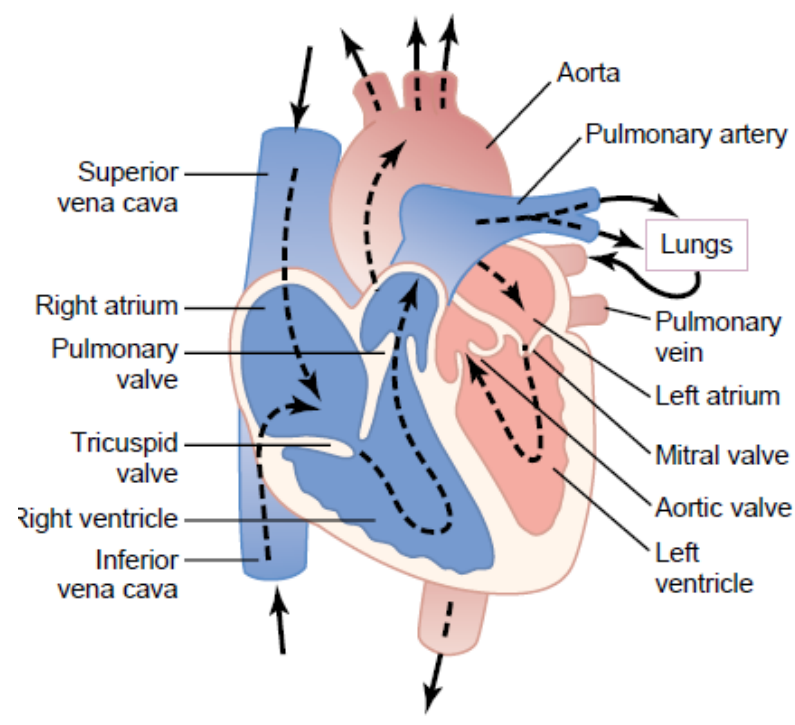

Figure 1 - Structure of the heart, and course of blood flow (adapted from [7]).

\subsection{Problem}

VAE is a complication caused by air bubble accumulation in the right side of the heart as result of pressure gradients between the heart and the incisional area [2]. Knowing the physiology of the heart is important to understand this event that causes many health problems like stroke, obstruction of pulmonary blood flow, and cardiovascular collapse [3].

Both volume and rate of air accumulation are dependent on the size of the vascular lumen as well as the pressure gradient (Figure 2). These factors determine the morbidity and mortality of any episode of VAE as well as the position of the patient [3, 4]. Neurosurgeries have a high risk of VAE episodes since, as can be seen in Figure 2, the pressure gradient of the head is negative when compared with the atmospheric pressure, so the probability of air entry in the blood flow is much higher. 


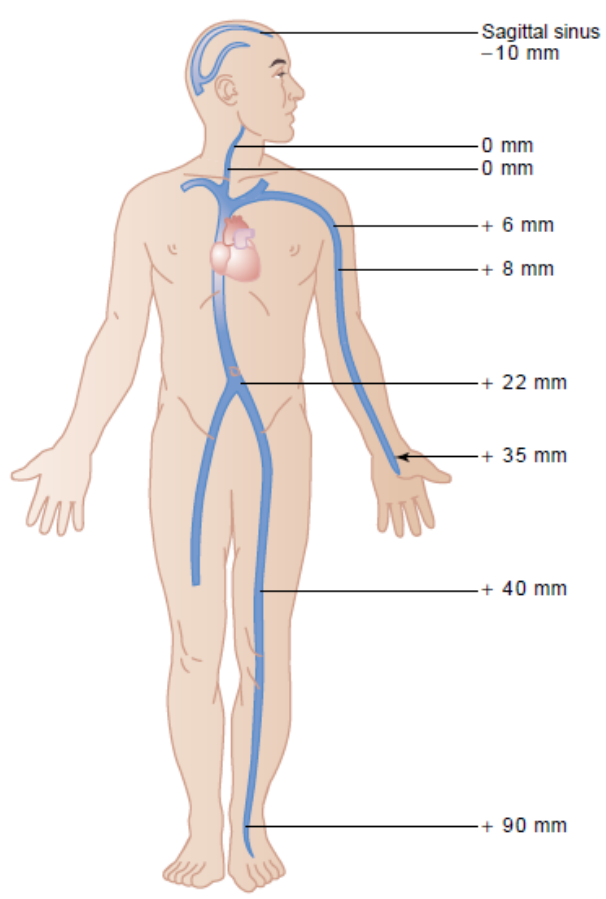

Figure 2 - Pressure gradients of different parts of the body (adapted from [7]).

Pathophysiologic pathways are highly dependent on the volume of air accumulated within the right ventricle. If the rate of embolism is high (approximately $5 \mathrm{ml} / \mathrm{kg}$ ), the probability of air bubble accumulation in the heart is higher. As consequence, the normal blood flow is interrupted. This outflow obstruction may be the result from the inability to decompress the tension of ventricular wall, which leads to heart failure and cardiovascular collapse. When the volumes of VAE are moderate, a decrease in cardiac output, hypotension, myocardial and cerebral ischemia, and even death may occur [5].

At the pulmonary level, an entrainment of air may lead to vasoconstriction, release of inflammatory mediators and bronchoconstriction. Not only negative pressure gradients but also positive pressure insufflation of gas may present a serious VAE hazard [5].

Main symptoms of VAE include chest pain, dyspnea, coughing [11], tachycardia, cyanosis [5] and sense of impending death [2, 12].

Relating the incidence of VAE with the position of the patient, neurosurgical procedures performed in the sitting position have the highest rate of VAE ( $80 \%$ for seated posterior fossa surgery) [13]. Neurosurgeries performed in the lateral, supine, or prone positions have an incidence ranging from $15 \%$ to $25 \%$ [3].

In dogs, the lethal volume of air when injected rapidly is $7.5 \mathrm{ml} / \mathrm{kg}$. In smaller animals such as the rabbit, the lethal volume is as low as $0.55 \mathrm{ml} / \mathrm{kg}$ [3]. In humans patients, the volume of gas tolerated is unknown, but accidental injections of air of between $100 \mathrm{ml}$ and $300 \mathrm{ml}$ or $3-5 \mathrm{ml} / \mathrm{kg}$ have been reported to be fatal $[1,3,5,11]$.

In the absence of a high level of suspicion, VAE may be difficult to diagnose because the signs and symptoms are nonspecific and may be transient [3, 11]. In one study of Vesely et al. 
$26.7 \%$ of the total patients with VAE episodes remained completely asymptomatic at the moment of the event [11].

Figure 3 presents a summarized graphical representation of possible sources of VAE, as well as the volume amounts which determine the gravity level, and respective symptoms.

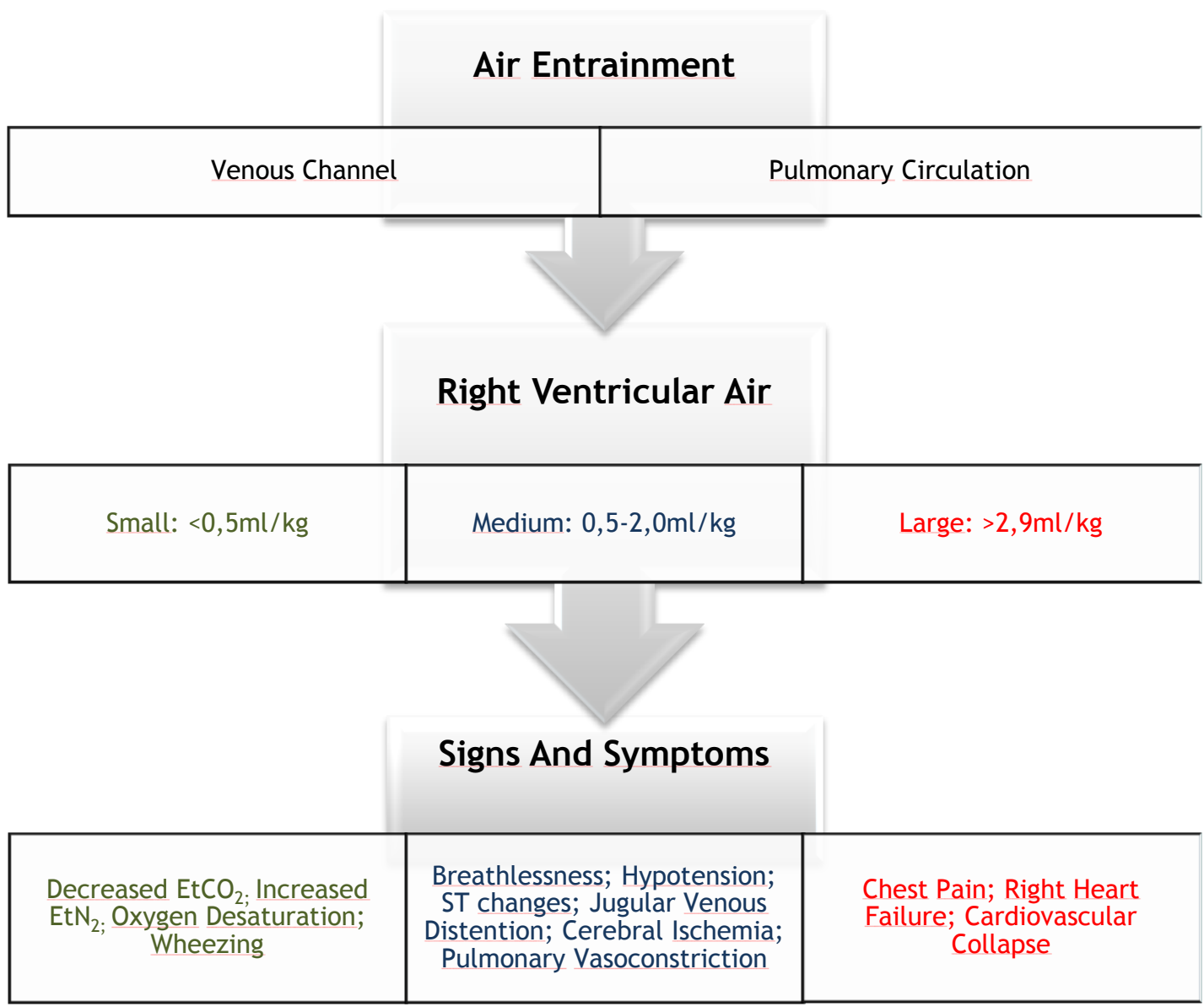

Figure 3 - Adverse sequels from air embolism are dependent principally on the volume of air, as well as the rate of entrainment. Higher volumes of air have substantial effects on the cardiovascular, pulmonary, and cerebral organ systems. $\mathrm{ETCO}_{2}$ : end-tidal carbon dioxide; $\mathrm{ETN}_{2}$ : end-tidal nitrogen (adapted from [4]).

Neurosurgical cases remain the highest risk of VAE as a consequence of elevated incision site, relative to the heart, and numerous large and uncompressed venous channels in the surgical field $[1,5]$. The list of surgical procedures with major probability of VAE is presented in Table 1. 
Table 1 - Surgical Procedures associated with VAE and respective rate of incidence (adapted from [4]).

\begin{tabular}{ll}
\hline \multicolumn{1}{c}{ Procedures } & \multicolumn{1}{c}{ References and Known Incidence } \\
\hline \hline Sitting Position Craniotomies & Harrison et al. (9,3\%), Bithal et al. \\
& $(27,4 \%)$, Losasso et al $(27,4 \%)$ \\
Posterior Fossa Procedures & Papadopoulos et al (76\%) \\
Craniosynostosis Repair & Tobias et al (82,6\%) \\
Cervical Laminectomy & Lopez et al (23\%) \\
Spinal Fusion & Latson (10\%) \\
\hline
\end{tabular}

Further information on the intraoperative management and complications are presented in Appendix III and IV.

\subsection{Detection}

The monitoring devices that are used to detect VAE should be sensitive, easy to use, and noninvasive. The selection depends on the position of the patient, the expertise of the anesthesiologist in using the device, and the medical condition of the patient [4]. A list of the principal detection methods/devices is shown in Table 2, as well as advantages and disadvantages of each one.

Table 2 - Comparison of methods of detection of VAE (adapted from [14]). $\mathrm{ET}_{\mathrm{CO} 2}=$ End-Tidal Carbon

Dioxide Gas; $\mathrm{ET}_{\mathrm{N} 2}=$ End-Tidal Nitrogen Gas; $\mathrm{N}_{2} \mathrm{O}=$ Nitrous oxide; PA=Pulmonary Artery; $\mathrm{TCD}=$ Transcranial Doppler; TEE $=$ Transesophageal Echo.

\begin{tabular}{llll}
\hline \multicolumn{1}{c}{ Method of Detection } & Sensitivity & Invasiveness & \multicolumn{1}{c}{ Limitations } \\
\hline \hline TEE & High & High & $\begin{array}{l}\text { Expensive, Invasive } \\
\text { Obese Patients }\end{array}$ \\
Precordial Doppler & High & None & $\begin{array}{l}\text { Fixed Distance, Small } \\
\text { PA Catheter }\end{array}$ \\
Orifice
\end{tabular}


The correct selection and use of these devices contribute to an early detection and prompt treatment, factors that limit morbidity and mortality of VAE [15]. It is possible to read more about these detection methods in appendix $\mathrm{V}$.

As may be seen in Table 2, the precordial Doppler is the device with fewer disadvantages when compared with others, presenting a high sensitivity. For this reason, the precordial Doppler is one of the methods broadly used to monitoring VAE, namely, during neurosurgeries $[3,16]$. As the name of the device indicates, it uses the Doppler effect which consists in the change of the frequency of a wave in response to the blood flow relative to the Doppler probe.

This is a highly sensitive technique once it was demonstrated that it may detect as little as $0,25 \mathrm{ml}$ of air $(0,05 \mathrm{ml} / \mathrm{kg})[1,3,4]$.

The Doppler probe is normally placed along the right sternal border (between the third and sixth intercostal spaces) since good results were obtained in adults and children, using these landmarks [3, 4, 17]. Generally, the positioning is confirmed by an injection of some millimeters of saline fluid [4].

The first discernible evidence of VAE is a change in the character and intensity of the emitted sound [4] namely the classic mill-wheel murmur [2, 3]. This sound reflects the turbulent resonance of normal blood flow passing abruptly through the right cardiac chambers.

Major impediments in the use of this device include sound artifacts during the use of electrocautery, prone and lateral patient positioning [4]. A limitation is the absence of air volumes quantification. Such information is essential for the anesthesiologist to prescribe suitable clinical treatments [8, 18]. Besides these limitations, many studies advise the inclusion of the precordial Doppler in the anesthetic plan once it is the most cost effective, easy to use, and least invasive of the high sensitivity monitoring devices $[3,4,16,18,19]$.

In order to improve the performance of the precordial Doppler, some studies have been done. In [17] the authors studied the precordial Doppler chest positioning that maximizes its detection sensitivity. The objective was to identify procedures to facilitate successful positioning of the precordial Doppler, and to estimate the effects of probe malposition comparing the Doppler responses to carbon dioxide $\left(\mathrm{CO}_{2}\right)$ and a normal saline (NS) administered via peripheral and central IV catheters, at various Doppler probe positions. The Doppler used was a two probes ultrasound.

To make this experiment, 40 patients undergoing craniotomy in recumbent position were distributed into two groups, A and B. In the first group, the probes were placed in the right and left parasternal locations. In the second group, the first probe was placed at the conventional location $[3,4,17]$ and the second was malpositioned as far laterally over the left precordium. To compare the detection rates, four injections consisting in two boluses of 
$10 \mathrm{ml}$ of NS and two boluses of $1 \mathrm{ml}$ of $\mathrm{CO} 2$ via peripheral and central venous catheters, were administered.

The authors observed that the left parasternal probe detected a response to test injections in all patients while right parasternal probe did not.

Analysis of results obtained for group $B$, showed that the right parasternal probe detected more positive responses to test injections than the extreme left lateral precordial probe.

Despite the differences between groups, only the values for centrally injected $\mathrm{CO}_{2}$ and between centrally injected $\mathrm{NS}$ and $\mathrm{CO}_{2}$, in group $\mathrm{B}$, were statistically significant $(\mathrm{P}<0,05$ and 0,015 respectively).

The authors concluded that a left parasternal placement results in more frequent detectable cardiac tones, and that sensitivity of Doppler when placed in left parasternal is at least as good as sensitivity of Doppler when placed in right parasternal. Besides that, left lateral precordial probe locations frequently fail to detect intravascular bubbles (false negative response rate) that are detected by probes located in parasternal location.

Other studies try to validate de use of precordial Doppler to diagnose VAE, as proposed in [19] where the authors combined this device (previously modified to minimize interferences by electrocautery) with right atrium catheters in patients undergoing surgeries in upright position. This study included 33 patients during surgical procedures to posterior fossa, 29 during cervical laminectomy and 7 during temporal craniotomy. During surgery, whenever changes in Doppler sound or in vital signs were detected, the right arterial catheter (RAC) was aspirated, and therapeutic measures of air embolism instituted.

Based on changes in Doppler sound, diagnosis of VAE was suspected on 27 occasions, being confirmed by aspirating air from the right atrium in 20 episodes. Clinical signs of VAE were detected in one of the 20 confirmed cases. The remaining 7 cases demonstrated changes in Doppler sound characteristic of air embolism but were not confirmed by aspiring air from the right atrium. Two additional episodes were detected by systolic murmur and confirmed by aspiration of air from the right atrium.

The frequency of air embolism was higher in surgeries to posterior fossa (18 episodes), and was about half as frequent in cervical laminectomy and temporal craniotomy (11 episodes in 36 patients). By evaluation of the results, authors concluded that the Doppler device allows detection of air embolism even if the air volume was not alarming for the clinical state of the patient. Authors concluded also that the injection of $\mathrm{CO} 2$ into the right atrium as a test procedure could be helpful to assess placement of the Doppler probe.

As can be seen, several articles validate the utility of the precordial Doppler in the detection of VAE episodes, being a useful device to assist the decision of anesthesiologists.

Table 3 presents the preventive measures, monitoring and therapeutic management for different procedures with different risks of VAE. 
Table 3 - Preventive measures, patient monitoring and therapeutic management of VAE (adapted from [4]). End-tidal carbon dioxide $\left(\mathrm{EtCO}_{2}\right)$; end-tidal nitrogen $\left(\mathrm{EtN}_{2}\right)$; nitrous oxide $\left(\mathrm{N}_{2} \mathrm{O}\right)$.

Surgery or Invasive Vascular Procedure

\begin{tabular}{|c|c|c|c|}
\hline VAE RISKS & Low & Medium & High \\
\hline EXAMPLES & $\begin{array}{l}\text { Anterior Neck Surgery } \\
\text { Burr Hole Neurosurgery }\end{array}$ & Rapid Blood Transfusion & $\begin{array}{l}\text { Sitting Craniotomy; } \\
\text { Posterior Fossa/Neck; } \\
\text { Central Line Placement; } \\
\text { Craniosynostosis }\end{array}$ \\
\hline $\begin{array}{l}\text { PREVENTION AND } \\
\text { MONITORS }\end{array}$ & $\begin{array}{l}\text { Patient Positioning; } \\
\text { Hydratation; } \\
\text { Hemodynamic } \\
\text { Monitoring; Oxygen } \\
\text { saturation; } \mathrm{EtN}_{2} ; \mathrm{EtCO}_{2}\end{array}$ & $\begin{array}{c}\text { Patient Positioning; } \\
\text { Hydratation; Hemodynamic } \\
\text { Monitoring; } \mathrm{Oxygen} \\
\text { saturation; } \mathrm{EtN}_{2} ; \mathrm{EtCO}_{2} ; \\
\text { Avoidance } \mathrm{N}_{2} \mathrm{O} ; \text { Precordial } \\
\text { Doppler }\end{array}$ & $\begin{array}{l}\text { Patient Positioning; } \\
\text { Hydratation; } \\
\text { Hemodynamic } \\
\text { Monitoring; Oxygen } \\
\text { saturation; } \mathrm{EtN}_{2} ; \mathrm{EtCO}_{2} ; \\
\text { Avoidance } \mathrm{N}_{2} \mathrm{O} ; \\
\text { Precordial Doppler }\end{array}$ \\
\hline MANAGEMENT & \multicolumn{3}{|c|}{$\begin{array}{c}\text { Stop Entrainment; Increased Inspiratory Oxygen; Hemodynamic Support; Central } \\
\text { Venous Catheter Aspiration; Hyperbaric oxygen; Chest Compression and } \\
\text { Cardiopulmonary Resuscitation }\end{array}$} \\
\hline
\end{tabular}

\subsection{Summary}

This chapter presented some notions on the physiology of the heart as well as VAE, with associated health problems and the importance of detecting these episodes as fast as possible. Management of VAE is very important in order to actuate adequately after VAE detection. There are many monitoring protocols that include the use of precordial Doppler sound monitoring, since it is a non-invasive and one of the most sensitive detection methods available.

The importance of DHS monitoring in the timely detection of VAE was shown, demonstrating the need for robust automatic detection methods that may aid anesthesiologists in their clinical activity. 


\section{Chapter 3}

\section{State of the Art}

To understand the sensitivity of precordial Doppler, and how the DHS may be used to extract information about the air volume entry; a few studies have been published. Only one research group developed and published work in this area, by analyzing VAE episodes in Dogs through DHS signal processing.

Signal Processing has a high relevance in anesthesia, since most of the devices used to monitor the patient's state, show the information retrieved from physiological signals, using signal processing techniques. Some of these techniques were explored in DHS analysis, and will be presented in this chapter.

\subsection{Doppler Heart Sound Analysis}

In "Fast Detection of Venous Air Embolism in DHS Using Wavelet Transform" [16], the authors study both the qualitative and quantitative properties of the DHS during VAE, by injection of a known volume of air in the vessels of dogs. The spectral characteristics of the embolic heart sound (EHS) were investigated using the Wavelet Transform (WT).

This method decomposes a signal into components that appear at different scales and can be used to analyze the frequency components. A wavelet is a function with average equal to zero and, considering a signal $f(x)$ at scale $s$ and position $x$, it is given by the convolution product:

$$
W_{s} f(x)=f^{*} \vartheta_{s}(x)=\int_{-\infty}^{+\infty} f(t) \vartheta_{s}(x-t) d t
$$

Where

$$
\vartheta_{s}(x)=\frac{1}{s} \vartheta\left(\frac{x}{s}\right)
$$

The fact that $\vartheta_{s}$ decreases as the scales decreases too, turns the wavelet sensitive to finer details. The scale of the wavelet is important once it defines the size and regularity of the characteristics extracted by WT. [20]

Based on its properties the WT of the DHS signal was computed using the following algorithm: 


$$
\begin{aligned}
& S_{2^{j}} f(x)=\sum_{k \in Z} h_{k} S_{2^{j-1}} f\left(x-2^{j-1} k\right) \\
& W_{2^{j}} f(x)=\sum_{k \in Z} g_{k} S_{2^{j-1}} f\left(x-2^{j-1} k\right)
\end{aligned}
$$

Where $S_{2^{j}}$ is a smoothing operator at scale $2^{j}$ and $g_{k}$ and $h_{k}$ are the corresponding impulse responses of two $2 \pi$ periodic functions $H(w)$ and $G(w)$.

From the two previous equations, WT can be viewed as successive filtering of the DHS signal. Once Fourier Transform of the WT is

$$
\begin{gathered}
G(w) F(w) \varphi(w), \quad j=1 \\
G(w) H(w) F(w) \varphi(w), \quad j=2 \\
G\left(2^{j-1} w\right) H\left(2^{j-2} w\right) \ldots H(w) F(w) \varphi(w), \quad j>2
\end{gathered}
$$

Where $F(w) \varphi(w)$ correspond to the Fourier Transform of the original signal and the successive scales $2^{j}$ are equivalent to a bandpass filter as successively narrower bandwidths.

In this work, air injections with ascending volumes $(0.01,0.02,0.05$ and $0.10 \mathrm{ml})$, with an interval of 5 minutes between injections were administered. The audio output was digitized at $4 \mathrm{kHz}$ during 8 seconds for each air injection. The period of DHS signal with no injection was taken as the control. The total number of datasets collected was of 12 .

After data acquisition, Chan et al, applied a low pass filter to the DHS with a cutoff frequency of $3 \mathrm{~Hz}$ (corresponding to the average heart rate of the dogs). Figure 4 shows the focus of this study with the original DHS, the resultant signal envelope and the logical partition of DHS. The last, indicates the period of each heartbeat.

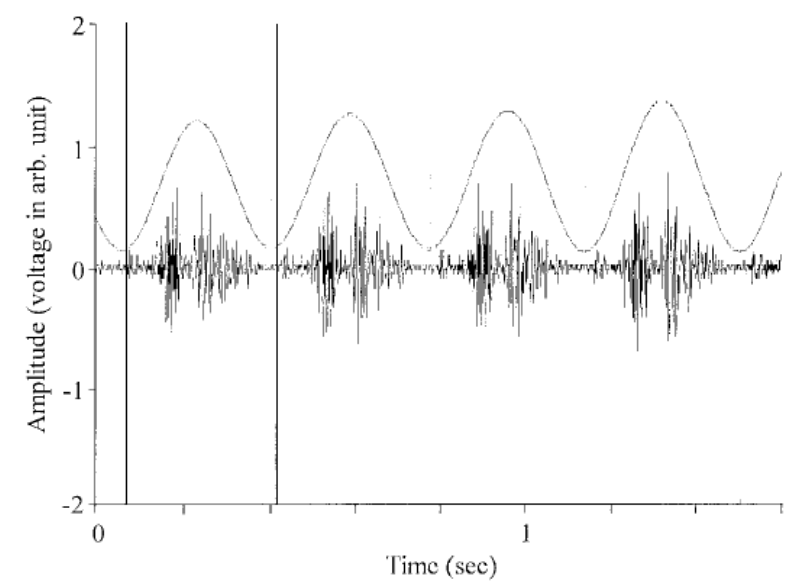

Figure 4 - Doppler heart sound signal and signal envelope obtained by low pass filtering. The local minima of envelope divides the signal into cardiac cycles (adapted from [16]).

Following, the waveforms and the spectra of one single cardiac cycle, with and without embolic air, were analyzed. When comparing these two situations, it is perceptible that the data corresponding to the embolic air presents higher frequency components. WT of the DHS signal was obtained for levels 1, 2 and 3 (Figure 5). j=1 shows more differences between the normal and embolic heartbeat. 


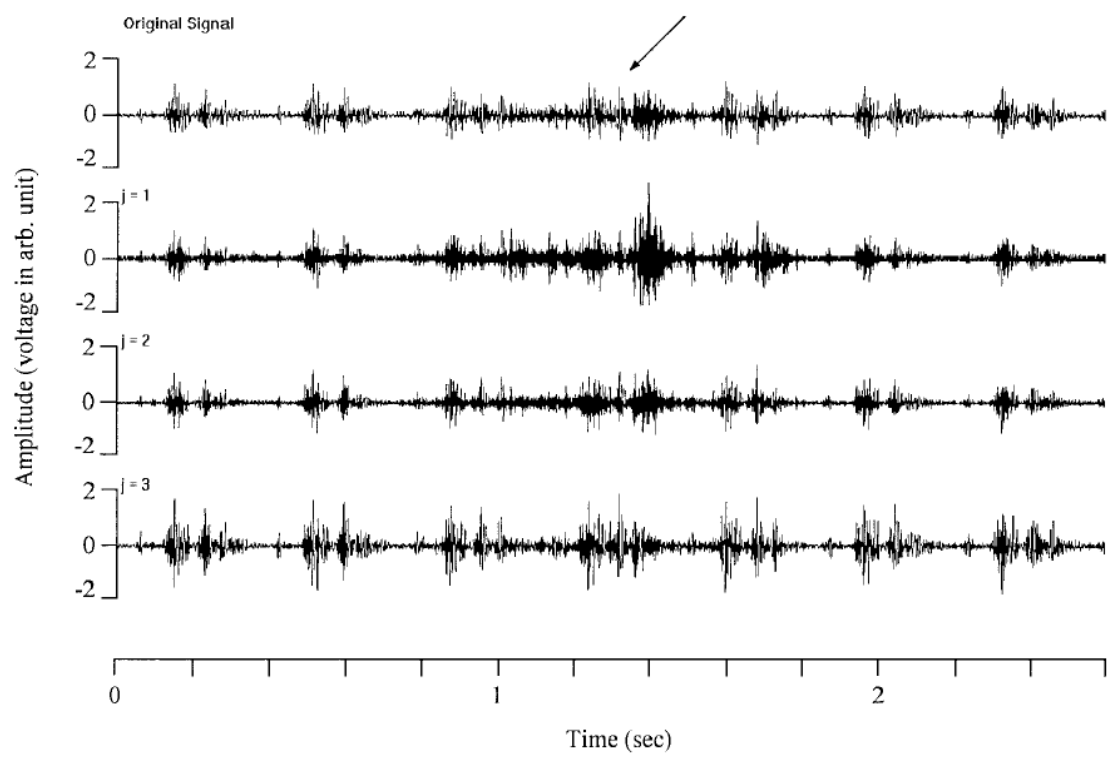

Figure 5 - DHS signal containing its WT at different scales ( $j=1$ to 3 ). The embolic heartbeat after $0,02 \mathrm{ml}$ of air infusion (marked by an arrow) was confirmed by an anesthesiologist after listening to the Doppler heart sound signal (adapted from [16]).

Following, the power of single heartbeats for the WT of DHS at different scales and the results normalized relatively to the control mean were calculated. Figure 6 shows these computations including the power data of the original DHS.

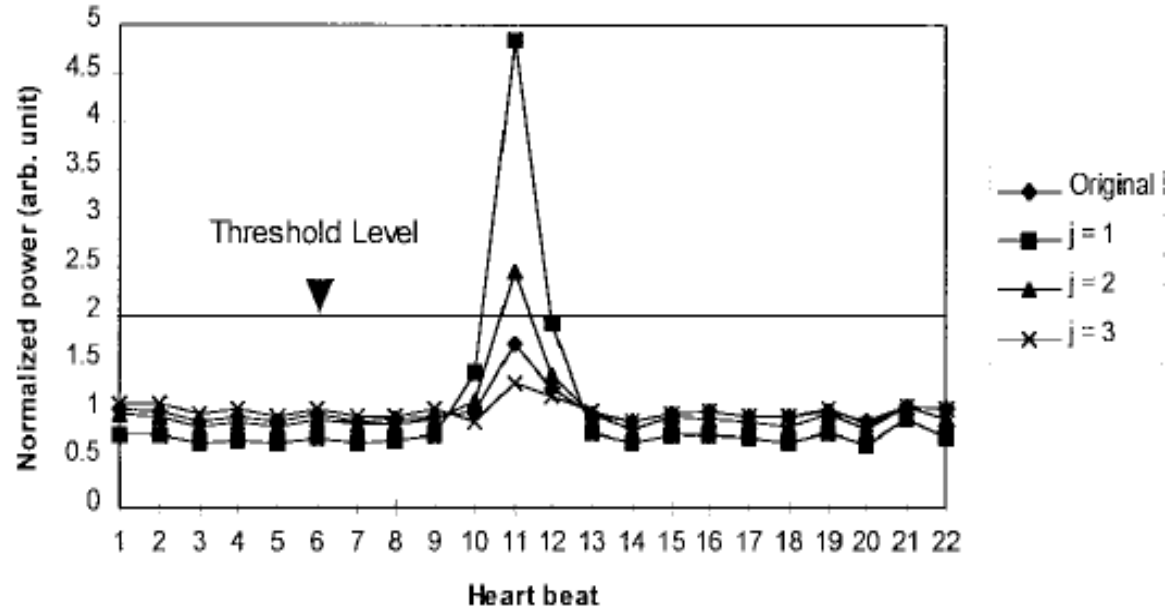

Figure 6 - Normalized power of individual heartbeats after WT of DHS. The increase of power (for $j$ = 1 and 2) identifies the embolic heartbeat above a threshold level that is two times the mean power level of the basal signal (adapted from [16]).

Cumulative embolic power (CEP) represents the sum of the normalized power of the heartbeats above the threshold and the embolic heart sound corresponding to each air injection. Results presented in Figure 7 show a linear relation between the CEP and the volume of air injected for all scales $(j=1$ to 3$)$. In figure $7 . a$ and $b$, it is possible to see the 
results of linear regression for $\mathrm{j}=1$ and 2 and the $\log$-log scale of this graphs in figure 7.c and d. The data relative to dog 3 is also shown in figure 7.e and $\mathrm{f}$.

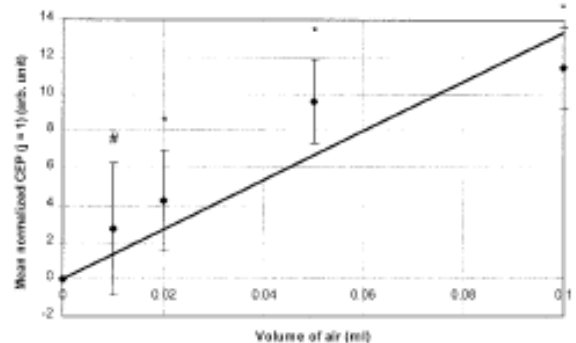

(a)

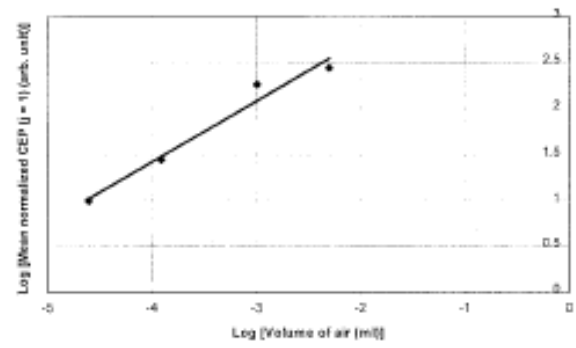

(c)

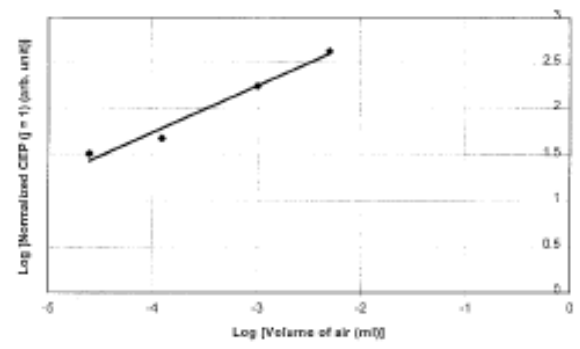

(o)

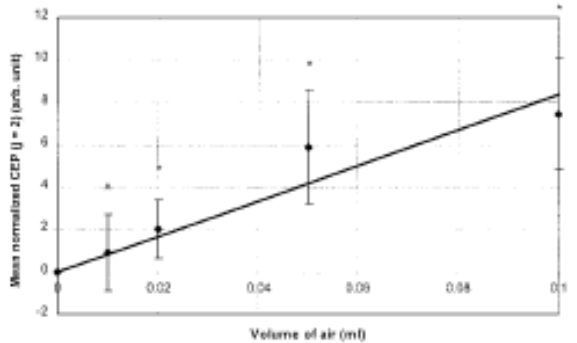

(b)

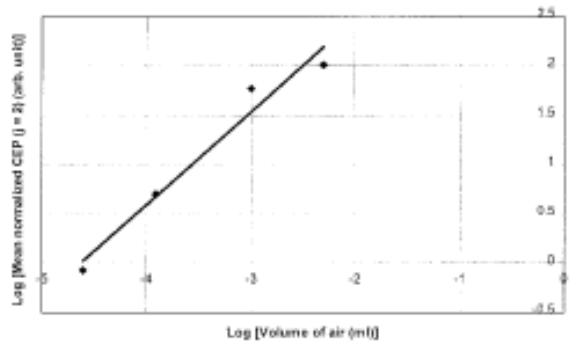

(d)

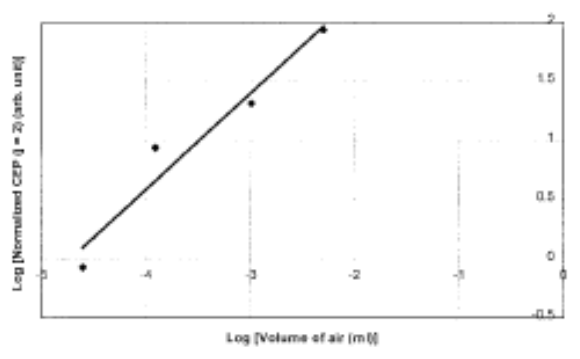

(f)

Figure 7 - Correlation between CEP and the volume of injected air at two different $j$ values: (a) $j=1$ and (b) $j=2$; with respective mean and standard deviation of 12 incidences of air injections obtained in four dogs. Figures 7(c) and 7(d) represents the linear regression in log-log scale of (a) and (b) and Figures $7(\mathrm{e})$ and $7(\mathrm{f})$ are the log-log plot of the normalized CEP versus the volume of injected air at $\mathrm{j}=1$ and $\mathrm{j}=2$, respectively, for average of 3 air injections in dog 3 (adapted from [16].

The same authors used different datasets in a different study [21] to compare the results with the results presented in [16]. They estimated the maximum frequency $\left(F_{\max }\right)$ of each heartbeat applying the percentile and threshold crossing method [22] and the power of high frequency (HF) components above $F_{\max }$ for each heartbeat. Both calculations were done to serve as controls.

Figure 8 presents the results for this method and the WT method. WT is better at level $\mathrm{j}=1$ and 2 , once the sensitivity and correlation with the volume of injected air are enhanced. 


\begin{tabular}{cccccc}
\hline Method & $j$ & Correlation & \multicolumn{2}{c}{$\begin{array}{c}\text { Sensitivity } \\
\text { (increase compared with control) }\end{array}$} \\
& $P$ & $r$ & $P$ & Injected air (ml) \\
\hline & 0 & $<0.0005$ & 0.62 & $<0.005$ & $>=0.05$ \\
WT & 1 & $<0.0005$ & 0.83 & $<0.01$ & $>=0.01$ \\
& 2 & $<0.0005$ & 0.81 & $<0.05$ & $>=0.01$ \\
$F_{\max }$ & 3 & $<0.0005$ & 0.55 & $<0.025$ & $>=0.05$ \\
HF power & & $<0.0005$ & 0.64 & $<0.005$ & $>=0.01$ \\
& $<0.0005$ & 0.68 & $<0.05$ & $>=0.02$ \\
\hline
\end{tabular}

Figure 8 - Correlation and sensitivity of WT and Fmax and HF power (adapted from [16]).

Then, the efficiency of WT, Fmax and HF power in terms of computation time was evaluated. WT method is less efficient so, it was necessary to redefine it and the low pass filter. The first refinement of WT consists in the simplification of equation (4) for $j=1$ by creating a new algorithm that only requires subtractions, reducing the time performance.

Low pass filter was substituted by moving average procedure [23] and the results of power calculation were incorporated. The result was the general equation "moving square average" (MSA):

$$
\operatorname{MSA}(x)=\operatorname{MSA}(x-1)+f^{2}(x+511)-f^{2}(x-513)
$$

Figure 9 represent the MSA's of original DHS and the WT of DHS for $j=1$. It is possible to see the enhancement of the contrast between the normal and the embolic signal power.

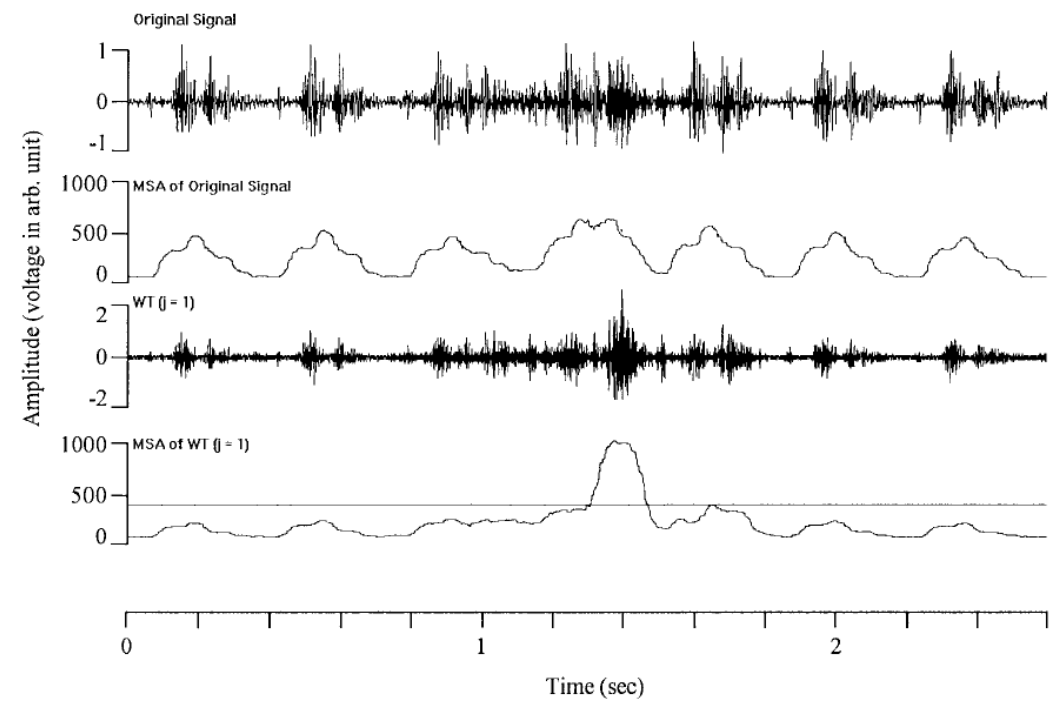

Figure 9 - MSA of DHS and WT at $j=1$. The embolic heartbeat is detected by the MSA signal crossing the threshold level in the WT (adapted from [16].

The main conclusions of this work are that WT of DHS provides a fast detection and accurate volume assessment of the embolic air. Once the high-frequency components appear in similar frequency intervals, it can be said that the air bubbles made a similar course through individual animals. However, the use of bandpass filters and of just one cuttoff frequency may hide details in high frequency components and in the estimation of correct volumes of embolic air. The fact of the WT could be applied to DHS at different scales, could 
provide extra information relative to the EHS. Finally, with this new algorithm, only a mean of $8 \mathrm{~ms}$ was needed to process one beat, demonstrating its feasibility for on-line applications.

\subsection{Real-Time Doppler Heart Sound Analysis}

The work of Chan et all continued and it is described in "A Real-Time Monitor using Wavelet Analysis of the Doppler Heart Sound for the Detection of Venous Air Embolism"[24] where a real-time monitor to detect VAE was developed using the Borland $\mathrm{C}++_{+}$program. Three procedures were applied to DHS signal: the WT at scale=1, the MSA of the waveletprocessed DHS, and peak location of MSA. The results of these processing techniques appear in the panel of the real time monitor, as can be seen in Figure 10. This monitor was conceived to be operated in three modes. In learning mode, it calculates the mean energy of the wavelet-processed DHS and the mean peak of MSA, important for normalization of the next modes; in calibration mode DHS in response to bolus injection of small air volumes are raised, to construct the calibration curve; finally, in monitoring mode, the DHS is analyzed in response to infusion of larger volumes. After this, the embolic energy of EHS is associated to the estimated calibration curve to assess the volume of air. The monitor shows also the cumulative embolic air as a function of infusion time.

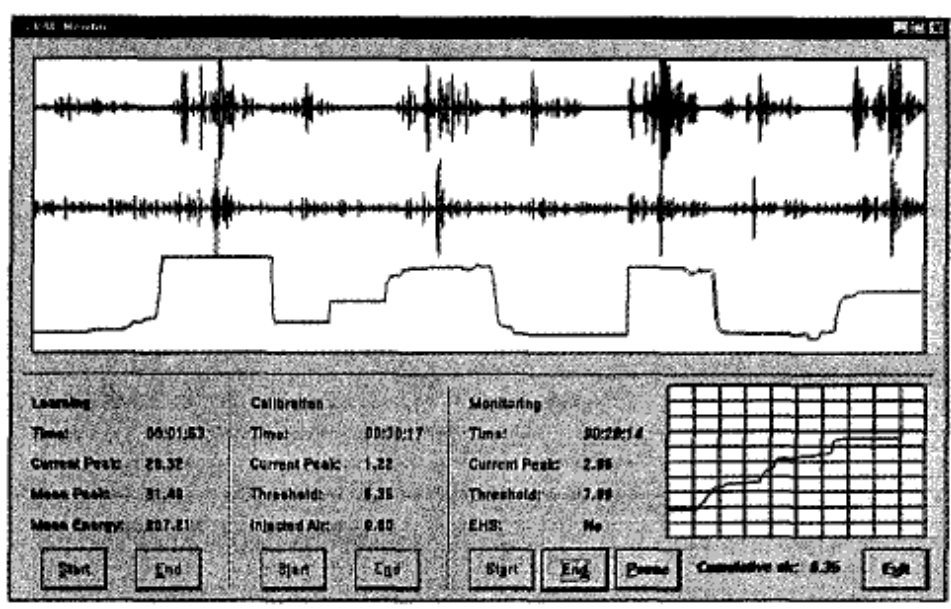

Figure 10 - Graphical interface of real-time monitor (adapted from [24]).

The application of this system was demonstrated in 4 dogs who received bolus injections of small air volumes $(0.01,0.02,0.05,0.07,0.10,0.15,0.20,0.30,0.40$ and $0.80 \mathrm{ml})$ followed by continuous infusion of larger volumes $(0.80,1.60,2.40,4.80$ and $9.60 \mathrm{ml})$ at various rates $(0,011-0,192 \mathrm{ml} / \mathrm{kg})$ over 5 minutes via right external jugular vein. The estimated cumulative embolic volume obtained for infusion of $9.60 \mathrm{ml}$ over time, is showed in Figure 11. 


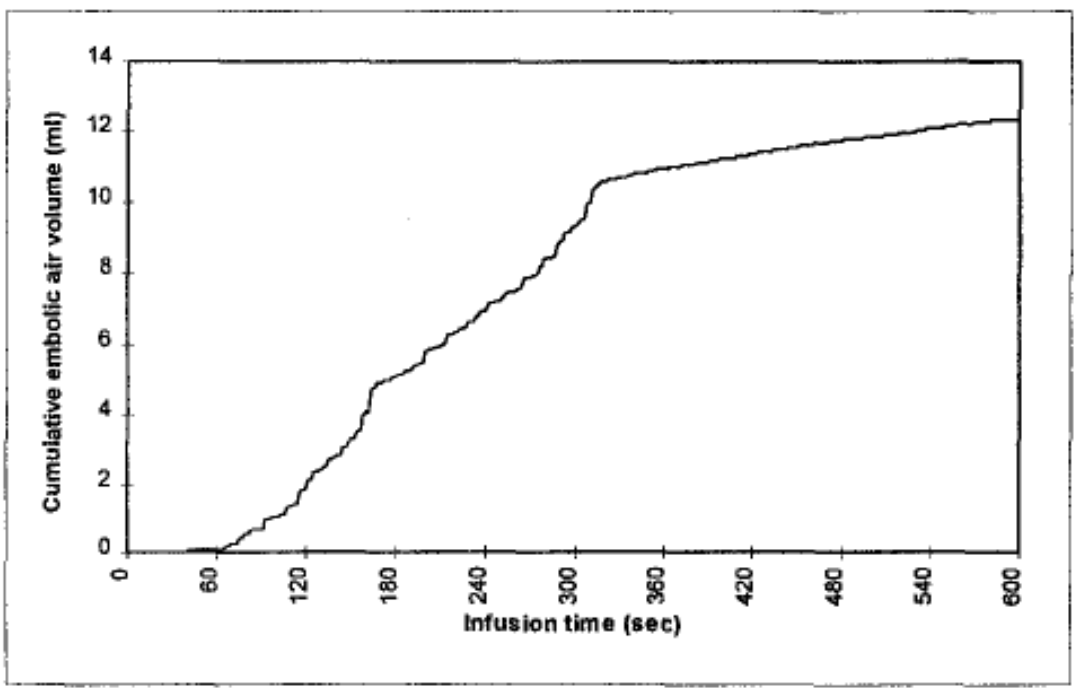

Figure 11 - Relation between the cumulative embolic air volume and the infusion time of $9.60 \mathrm{ml}$ air for $\operatorname{dog}$ A. The time of air infusion during the first 300 seconds (adapted from [24]).

It can be seen that the EHS with different embolic energy occurred in an intermittent way. The authors conclude that this happens because the air traveled through the external jugular vein to the right atrium, in a non-linear manner. On the other hand, there is a linear increase in cumulative embolic air volume when the administration of air is interrupted. This could be the result of re-circulation of the air within the heart chamber.

\subsection{Summary}

To identify forms to improve the detection of VAE episodes using the precordial Doppler, studies with signal processing of the DHS were explored.

The results available in the literature on the DHS analysis are limited to tests in animals. The analysis of methodologies for automatic detection of VAE on the DHS of human subjects is therefore imperative, although some limitations are imposed for the analysis of these subjects. 


\section{Chapter 4}

\section{Materials and Methods}

Following the motivation and state of the heart presented in the previous chapters, this chapter is focused on the description of the methodology of this study, namely data acquisition, signal processing, and evaluation of features extracted for DHS turbulence episodes detection.

\subsection{Clinical Protocol and Data Acquisition}

To perform data acquisition, a clinical protocol was designed and submitted for approval to the Department of Education, Training and Research, and to the Ethics Committee of Santo António's Hospital, Centro Hospitalar do Porto. After study approval, data collection was initiated.

During intraoperative management, the precordial Doppler was placed on the patient's chest according to manufacturer recommendations $[3,4,17]$. The device used was a precordial Doppler from Hadeco, model Smartdop $45^{\circledR}$ as can be seen in Figure 12.

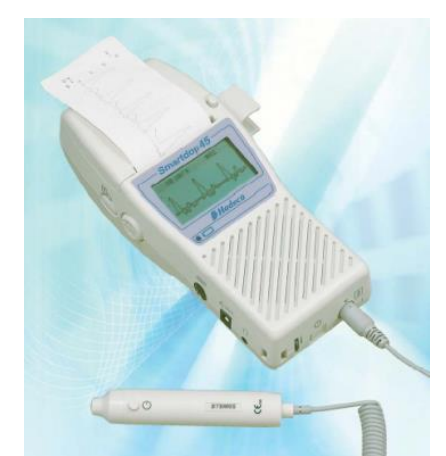

Figure 12 - Precordial Doppler from Hadeco, model Smartdop 45.

All patients were submitted to a total intravenous anesthesia (TIVA) of propofol and remifentanil [13]. Propofol has been shown to reduce the cerebral metabolic requirement of oxygen, thereby reducing cerebral blood volume. Thus, cerebral perfusion is maintained and 
oxygenation is allowed to areas of the brain that may be at risk of ischaemia. Remifentanil is an opioid that contributes to hemodynamic stability and allows a more rapid emergence when compared with other opioids [7].

To study the Doppler sound and which features allowed a better discrimination between normal blood flow and turbulent blood flow, the designed clinical protocol included a series of saline injections through peripheral and central catheters, at different rates and volumes of infusion, as way of study how these conditions affect changes in Doppler sound. The protocol was designed in this way because injection of air bubbles was not viable, and the occurrence of VAE is low for the available time span. The administrations of saline started after the patient was stabilized following induction. In total, each patient received 16 saline injections (with intervals of 15 seconds) with volumes of $1 \mathrm{ml}, 5 \mathrm{ml}, 8 \mathrm{ml}$, and $10 \mathrm{ml}$ at two distinct administration rates (one as slowly as possible and the other faster) by peripheral and central catheters. Each group of 16 infusions had to be administrated by the same anesthesiologist to mimic the two rates. Patients that fulfilled inclusion criteria were enrolled in this study after signing the informed consent (more details can be seen in Appendix VI, namely the approved clinical protocol). Besides analyzing different turbulence patterns in response to fast and slow saline administration, we were interested in analyzing if the administration catheter also had influence on these patterns.

Data was collected using the Rugloopll Waves, a software that synchronizes data from the different anesthesia monitors, including the precordial Doppler. Besides data from the monitors, demographic data of the patients was registered. DHS was collected at $8 \mathrm{kHz}$, and all injection moments were registered by the researcher for the following analysis.

\subsection{Heart Sound Segmentation}

This work is based on the rational that after the infusion of each saline, changes in the Doppler sound may be detected due to turbulent blood flow through the heart. In a first phase, heart sounds need to be detected to extract and study different features of the signal. MATLAB 2012 was used for signal processing.

\subsubsection{Signal Pre-Processing}

After data collection, the DHS signals were downsampled to $2 \mathrm{kHz}$. One of the objectives is to make Doppler sound acquisitions in different patients and compare the results obtained. Since the sets of data are heterogeneous it is necessary to normalize the signals. Normalization is a basic statistical operation where signals are scaled in a heterogeneous way, so that they may be compared. Normalization also facilitates the definition of broader thresholds [25].

After normalization, signals were analyzed in frames of 3 seconds corresponding to the DHS, since this is the adequate time to detect at least one complete cardiac cycle [16]. 


\subsubsection{Signal Filtering}

Since DHS may be contaminated by noise and the frequency band of interest is known, pre-processing of the signal included filtering the unwanted frequency components. Chan et al demonstrate that, in Dogs, the spectrum of a normal heartbeat is localized between 0 and $500 \mathrm{~Hz}$, and the spectrum of an embolic heart beat is localized between 0 and $1000 \mathrm{~Hz}$ [16].

A Butterworth low pass filter was applied to the DHS with a cutoff frequency of $900 \mathrm{~Hz}$. The filter was applied in both directions to avoid phase distortion. This filter is defined by the property that the magnitude response is maximally flat in the pass-band and is monotonic in the pass-band and the stop-band.

The Savitzky-Golay filter [26] was also implemented, because it smooths the DHS [27]. To do that, a convolution process is applied [28, 29], being one of the functions a subset of DHS signal and the other a low-degree function. They are fitted by the method of linear least squares, resulting in a smoothed signal [26].

To apply the Savitzky-Golay filter to the DHS, a polynomial of order 3 was chosen since the Doppler heart sound has the shape of a sinusoid. The chosen frame size was 21 because higher frame sizes highly distort the signal, as may be seen in figure 12 .
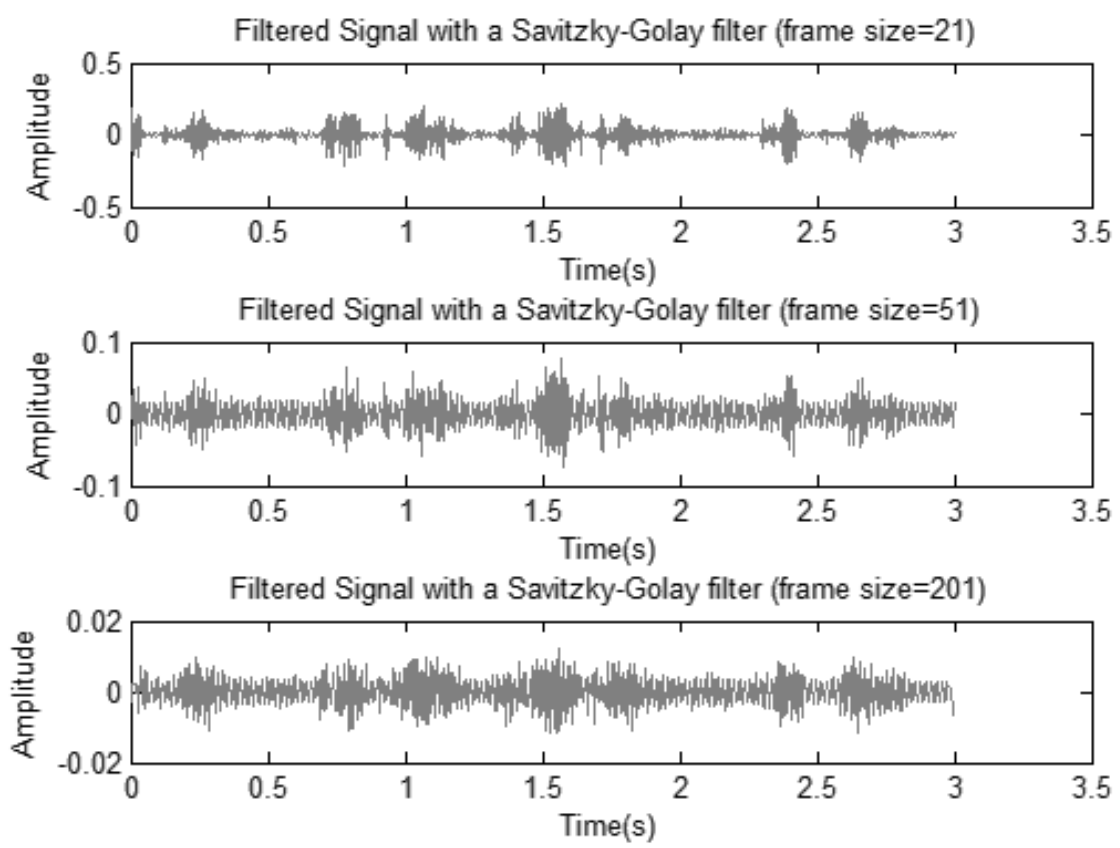

Figure 13 - Filtered signal after the application of Savitzky-Golay filter with different frame sizes (21, 51 and 201, respectively).

These filters were applied to the DHS with different purposes: the first to remove frequency components outside the band of interest, and later extract signal features for analysis; and the second to provide a smoothed version of the signal, and construct the envelope for heart cycle identification. Results of these filters may be seen in Figure 13. 

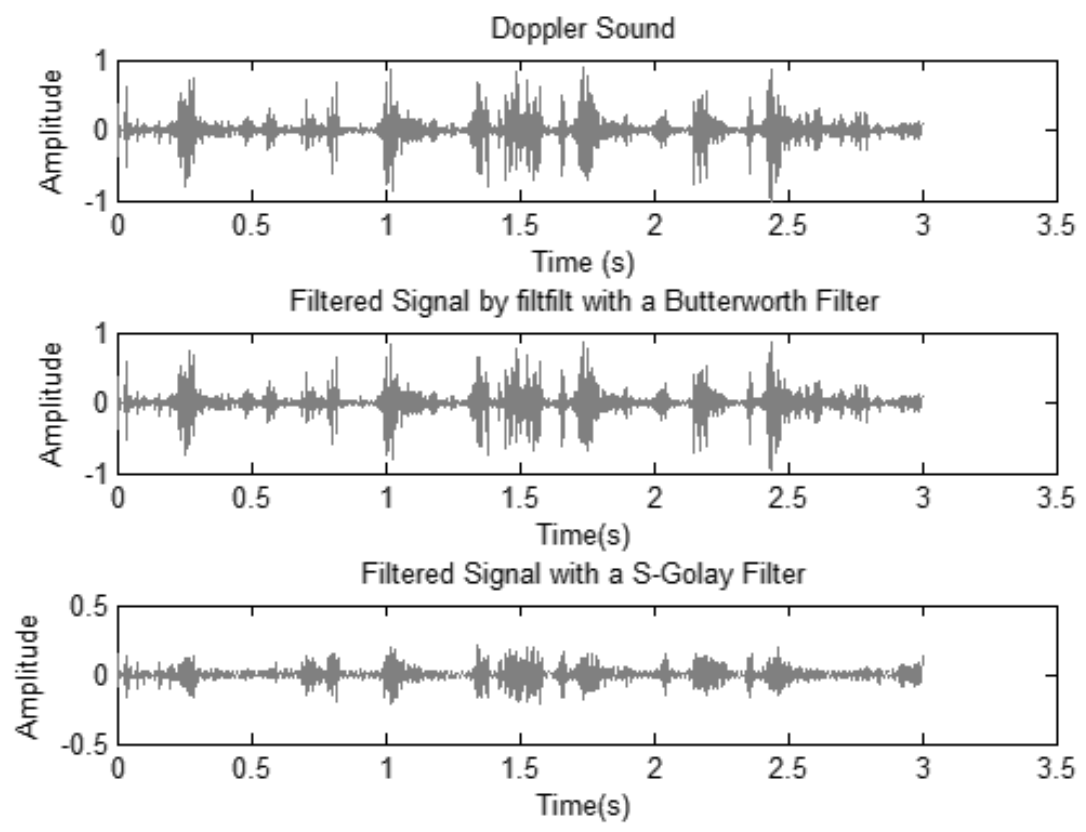

Figure 14 - Original signal and filtered signal using Butterworth and Savitzky-Golay filters.

\subsubsection{Envelope Design}

Following signal filtering the next step was to extract the signal envelope and segment the signal into heart cycles. The energy of the signal (Es) presented on Equation (9) was calculated using the Savitzky-Golay filtered DHS in windows of 0,5 s. The size of window chosen corresponds to the size of one cardiac event.

$$
E_{x} \triangleq \sum_{n=-\infty}^{\infty}|x[n]|^{2}
$$

Following, peaks of the envelope were detected using the function "findpeaks". This function detects peaks using predetermined characteristics. The chosen characteristic was "minimum peak distance with the value of $0,1 \mathrm{~s}$.

The detected peaks were then interpolated with a cubic Hermite spline to provide a smooth envelope of the signal. Results are presented in Figure 14, in a frame of 3 seconds of the filtered signal.

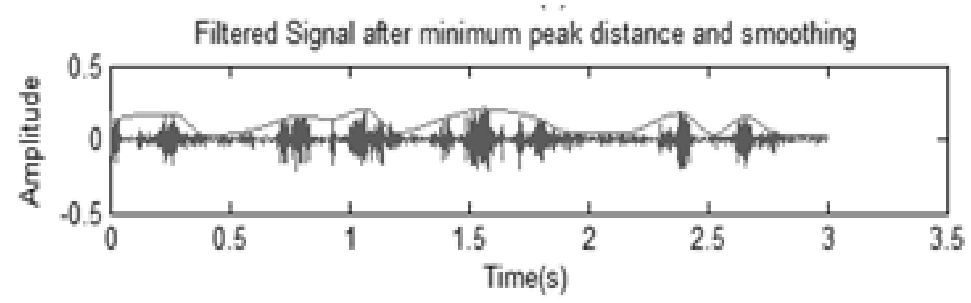

Figure 15 - Result of the application of findpeaks function with the parameter "minimum peak distance. 
The envelope obtained provides a smooth version of the signal amplitude variations in time that is ideal to detect the different heart cycle events, as it will be addressed in the next subsection.

\subsubsection{Identifications of Cardiac Cycles}

The smoothed envelope of the DHS amplitude was used to detect heart cycle events and also calculate the heart rate of the patient.

After obtaining the envelope, the cross-correlation was calculated for two consecutive frames as follows:

$$
(f * g)(t)=\sum_{m=-\infty}^{\infty} f^{*}[m] g[n+m]
$$

Where $f^{*}$ is the complex conjugate of $f$.

After this step, the maximum locals of the cross-correlation were detected and the heart rate was identified as the difference between the second and the first higher peaks as can be seen in Figure 15.

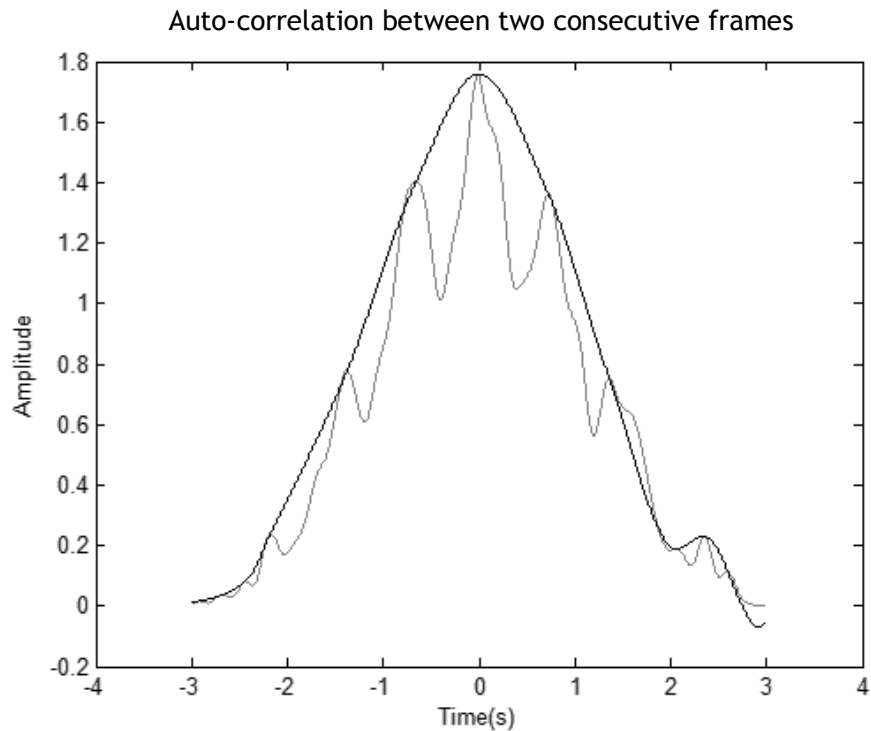

Figure 16 - Correlation between the two frames.

\subsection{Doppler Heart Sound Features}

As aforementioned, several signal features were evaluated in response to the different saline injections. The objective was to analyze time and frequency domain features that are able to differentiate patterns of normal blood flow, from turbulence patterns within the same subject. 


\subsubsection{Maximum Peak Frequency, Frequency at $95 \%$ and at $50 \%$ from Welch Periodogram}

Frequency content of the DHS was analyzed by estimating the PSD of the signal. Estimation of the PSD was done through the Welch method, which is a more robust estimate than the Periodogram Method reducing noise in the PSD.

The PSD Welch was obtained using a 150 points window with $50 \%$ overlap, and a Blackman window. All PSD shows that the power spectral density is higher at $200 \mathrm{~Hz}$, which is in consonance with the work of Chan et al, indicating that in a normal heart sound has higher power around $200 \mathrm{~Hz}$.

After obtaining the PSD for each heart cycle, three features were extracted: the frequency corresponding to the limit of 95\% of PSD power (f95), the frequency corresponding to $50 \%$ of the PSD power ( $f 50$ ) and the frequency corresponding to the maximum power peak of the PSD ( $\mathrm{fm}$ ). The method was applied to the signal using a moving window of 0,1 seconds and thee vectors stored.

\subsubsection{Maximum Frequency from Continuous Wavelet Transform (CWT)}

Continuous wavelet transform (CWT) analysis was also used to study the DHS. CWT uses inner products to find similarities between a signal and an analyzing function, the wavelet $(\psi)$. In other words, the signal is compared with stretched (scaling) or compressed versions of a wavelet. When a signal is compared with a wavelet at various scales and positions, the result is a function of two variables. Once the data analyzed is real-valued, the CWT is a realvalued function of scale and position [30].

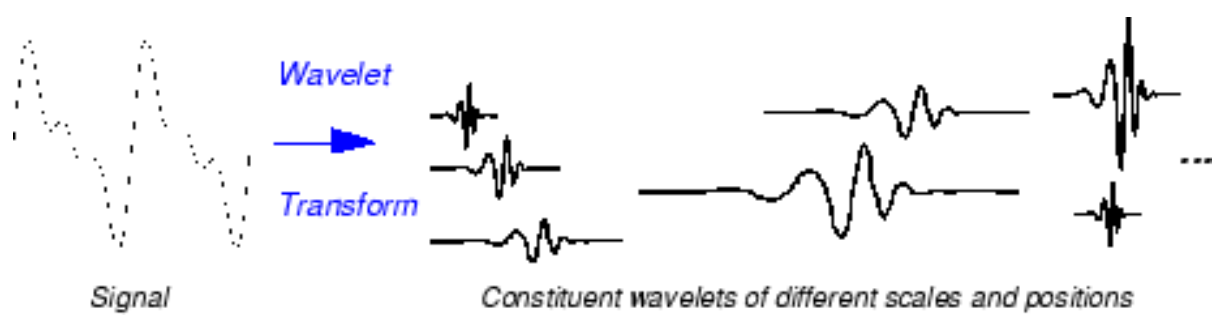

Figure 17 - Signal and constituent wavelets of different scales and positions.

The definition of CWT is given by

$$
C(a, b, f(t), \psi(t))=\int_{-\infty}^{+\infty} f(t) \frac{1}{\sqrt{a}} \psi *\left(\frac{t-b}{a}\right) d t
$$

Where $a$ is a scale parameter, $b$ is position and $*$ denotes the complex conjugate.

The scales used were between 1 and 10 at distance of 0,1 .

The choice of wavelet influences the coefficients obtained. There are various wavelets that could be used to obtain the coefficients. In this case, the chosen wavelet was the "Mexican Hat Wavelet" once it was demonstrated to provide good results in the analysis of the Doppler sound [31]. This wavelet has no scaling function and is derived from a function proportional to the second derivative function of Gaussian probability density function. 


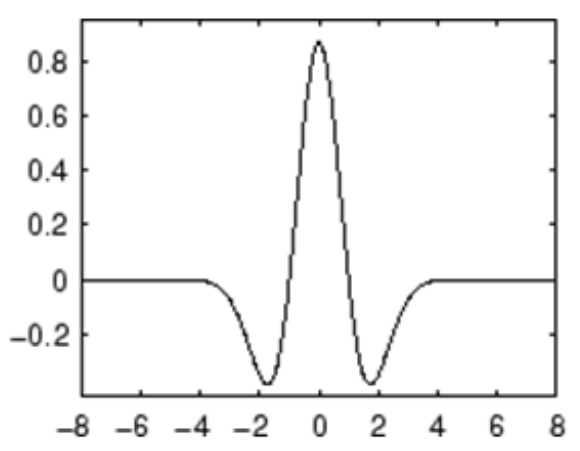

Figure 18 - Mexican Hat Wavelet.

CWT was applied to intervals of 0,1 seconds of the signal to extract the respective scales. With the coefficients obtained, the points of maximum energy of the signal and the respective scales were extracted. Using the function called "scal2freq" that correlates the frequencies and the scales, it was possible to know in which frequency band the energy was higher (freqwav) and store the values in a vector. Again, a vector with the average of this feature for the corresponding heartbeats of two seconds of each injection was created.

\subsubsection{Entropy}

An additional feature proposed in this study was the Shannon Entropy (E). This metric allows a quantification of the signal unpredictability and, when applied in finite signals, can be written as:

$$
E(X)=\sum_{i=1}^{n} p\left(x_{i}\right) \log _{b}\left(p\left(x_{i}\right)\right)
$$

Where $p\left(x_{i}\right)$ is the probability mass function of outcome $x_{i}$ and $b$ the base of the logarithm.

This feature was also implemented at each segment of 0,1 seconds and the values with the mean of this feature for the heartbeats of the two seconds after each infusion was stored in a vector for future evaluation.

\subsection{Features Evaluation}

After extracting all features and store them in a text file, these were exported to Excel (Office 2010) for the remaining processing. The features average value for each injection and patient were calculated. Also the graphical representation that relates the volume of infusion with the ratio injection/baseline changes for different administration rates and catheter were performed for all features. The ration injection/baseline was expressed by Equation (13):

$$
\text { Ratio }(\%)=\frac{\text { FeaturePostInj }}{\text { FeatureBaseline }}
$$

Where FeaturePostInj is the feature value of corresponding injection and FeatureBaseline is the feature value of each baseline. 


\subsection{Graphical User Interface (GUI)}

To allow automatic extraction of the features from each signal, a graphical user interface (GUI) was developed (Figure 18). The GUI allows the user to choose the signal to analyze, displaying patient's demographic information, estimated heart rate, and implemented features extraction.

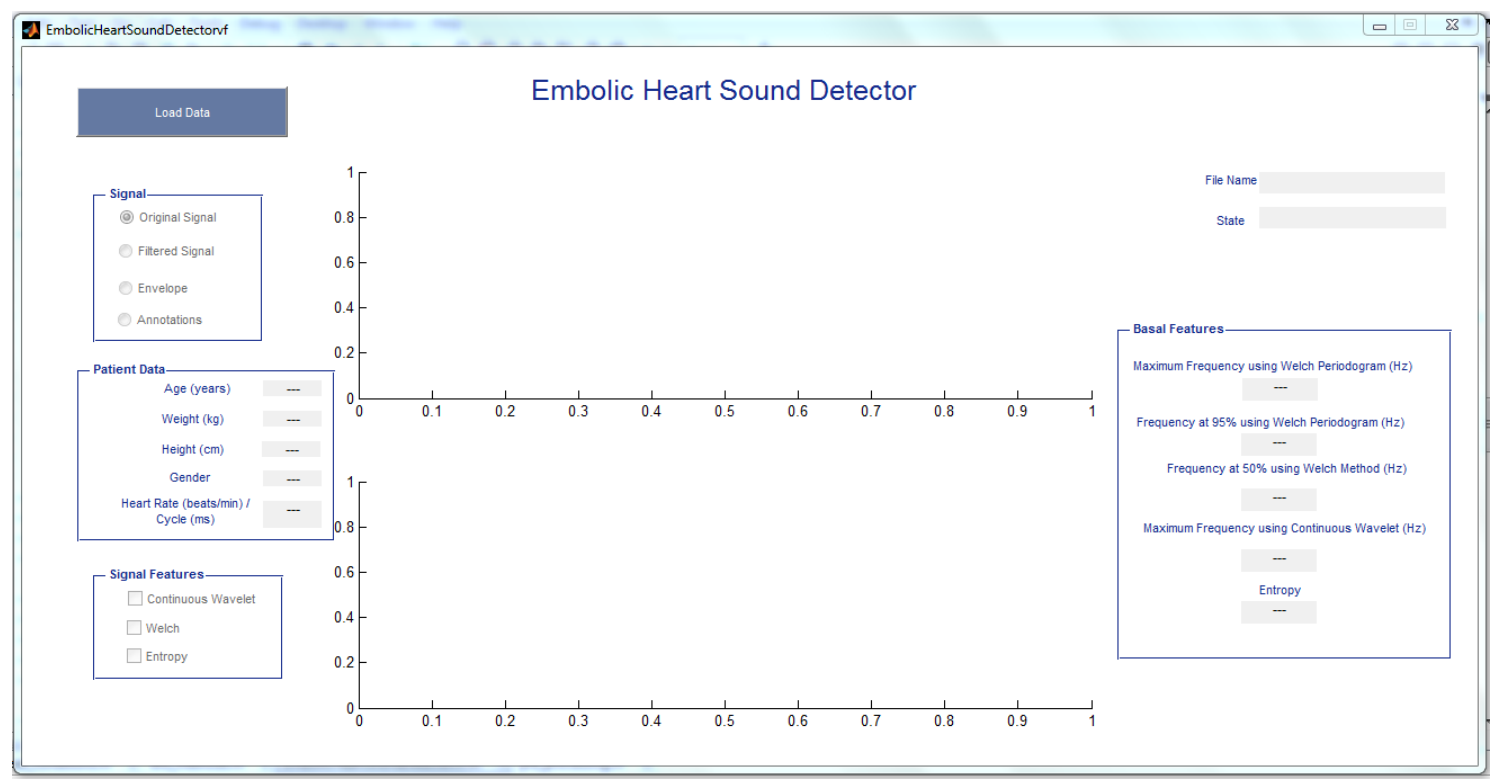

Figure 19 - Interface created to analyze the Doppler heart sound and present the results of the implemented methods.

\subsection{Summary}

This chapter presented the methodology of our study from data acquisition to signal processing and time-frequency features extraction.

Pre-processing of the DHS included signal normalization and filtering to remove out of band noise.

Envelope design and estimation of parameters like heart rate allow the extraction of the features corresponding to the heartbeat only.

The proposed methodologies were the presented in an offline analysis tool developed for DHS processing. 


\section{Chapter 5}

\section{Results and Discussion}

This chapter presents the results obtained after the implementation of the proposed methods. The results and methodology will be critically discussed.

\subsection{Data Collection and Pre-Processing}

As earlier described, the baseline DHS was analyzed considering the first 30 seconds of normal DHS. Following, infusion of saline at 2 distinct velocities, 4 volumes $(1 \mathrm{ml}, 5 \mathrm{ml}, 8 \mathrm{ml}$ and $10 \mathrm{ml}$ ) and 2 infusion catheters (periferic and central), making a total of 16 infusions with intervals of 10 to 15 seconds between them were administered to each patient enrolled in the study.

Six patients were enrolled in this study but only 4 acquisitions were afterwards studied since an error occur during the infusions of saline to the other two patients: the infusions where given by the taps corresponding to the periferic and central vias, nonetheless with extensions that may alter the turbulence, and therefore were not included in the remaining analysis. It is very important to control experimental conditions in order to be able to produced comparable and reproducible results.

All acquisitions where made in females (means: age=73 years; height=159 cm; heart rate $=75$ beats $/ \mathrm{min}$; weight $=62 \mathrm{~kg}$ ).

To eliminate frequencies corresponding to noise, two distinct filters were applied: Savitsky-Golay and Butterworth. If the goal was to estimate the heart rate of each patient, the Savistsky-Golay is a better approach because it smooths the signal allowing for the extraction of smooth DHS envelopes. If the objective was to study DHS features in response to saline injections, Savitsky-Golay is not a good choice because it actuates like a mask for higher frequencies. The lowpass butterworth filter is a better choice once it removes out of band noise, without phase distortion.

The smooth envelope allowed an accurate estimate of heart rate, and the function findpeaks allowed the identification of peaks relative to cardiac events (two for heartbeat), from which the proposed features were extracted. 


\subsection{Features Evaluation}

To evaluate turbulence episodes, the average value of the features of the DHS events in the $2 \mathrm{~s}$ following injection were evaluated, for each injection, for each patient: Mean_Mf95, Mean_Mf50,Mean_Mfm, Mean_ME and Mean_Mfreqwav. These features were normalized being divided by the basal features, meaning the ratio between features post-injection and baseline features, in terms of percentage (the Table with the feature values before normalization is presented in Appendix VII).

The normalized values were related with the infusion volumes in terms of rates and via, for each feature. Figure 20 presents these relations for frequency of $95 \%$ of Welch periodogram integral.
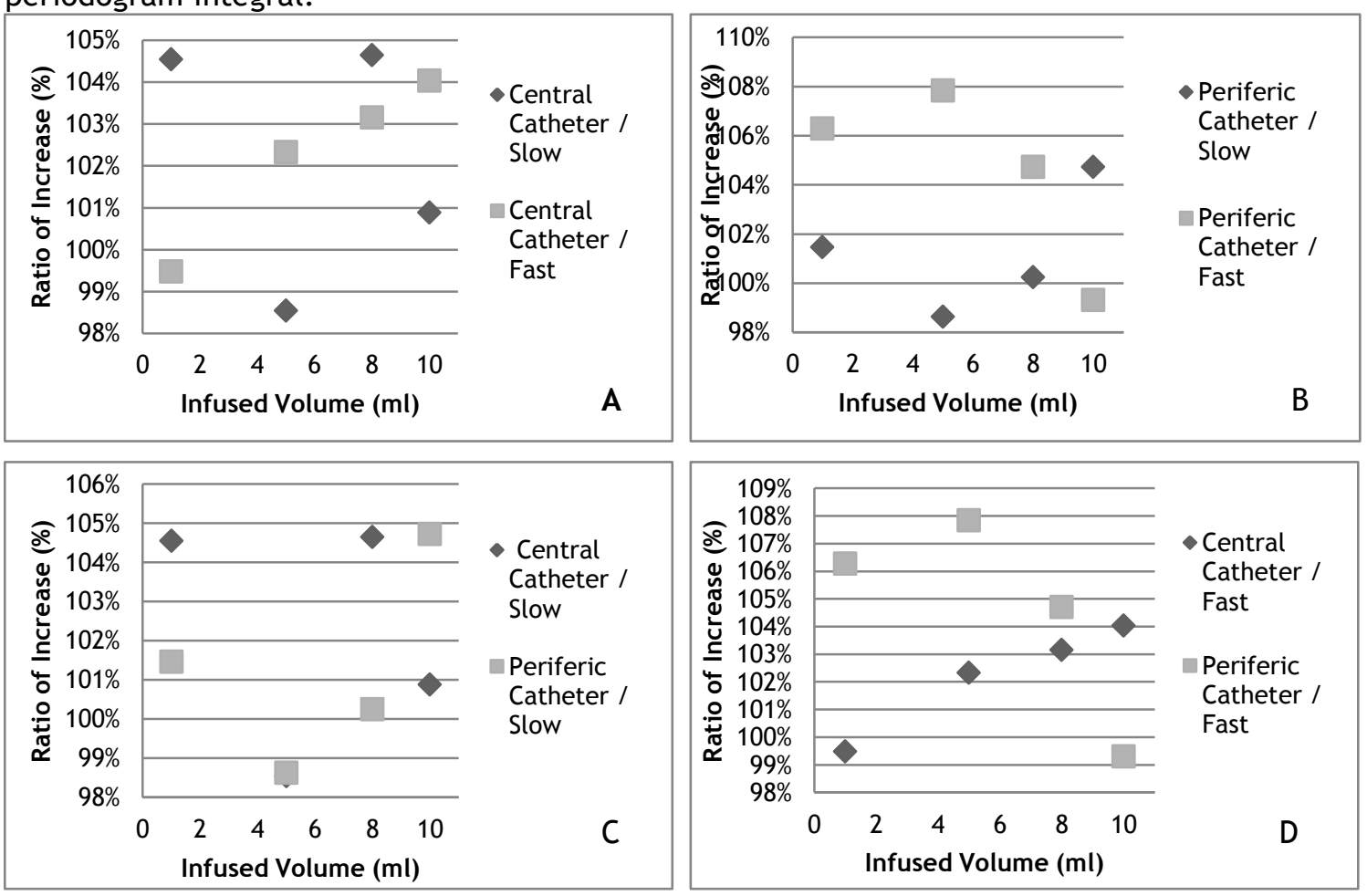

Figure 20 - Relation between the infusion volume and the ratio of increase (\%) of $\mathrm{f} 95$ for A) slow and fast rates of saline infusion via central catheter; B) slow and fast rates of saline infusion via periferic catheter; C) slow infusion of saline via central and periferic catheter; D) fast infusion of saline via central and periferic catheter.

Evaluating the rate of increase of $\mathrm{f} 95$ following infusions relative to basal values, figures $20 \mathrm{~A}$ ) and 20B) show that infusions with faster administration rate lead to a more pronounced change in Doppler characteristics as evaluated by f95, while slower rates not always are detectable, principally when the infusions are given by peripheric via as figure 20B) shows.

Observing Figures 20C) and 20D) it is clear that infusions via peripheric catheter are more easily detectable then via central. In fact, this result was not the expected because when the 
infusions are given via central catheter, the saline entries directly in the heart, so, the turbulence in the heart is higher and more detectable with a precordial Doppler. When the infusions are given by peripheral via, saline has to cross the bloodstream before arriving to the heart, so the turbulence effect is lost in the way and it turns more difficult to detect changes in Doppler sound.

In the majority of the cases, 995 following infusions increase relative to basal Doppler sound (rate of increase higher than 100\%).

Other feature evaluated was the $\mathrm{f} 50$ of the infusions relative to the basal values and its relation with rates of infusion and administration catheters as can be seen in Figure 21.
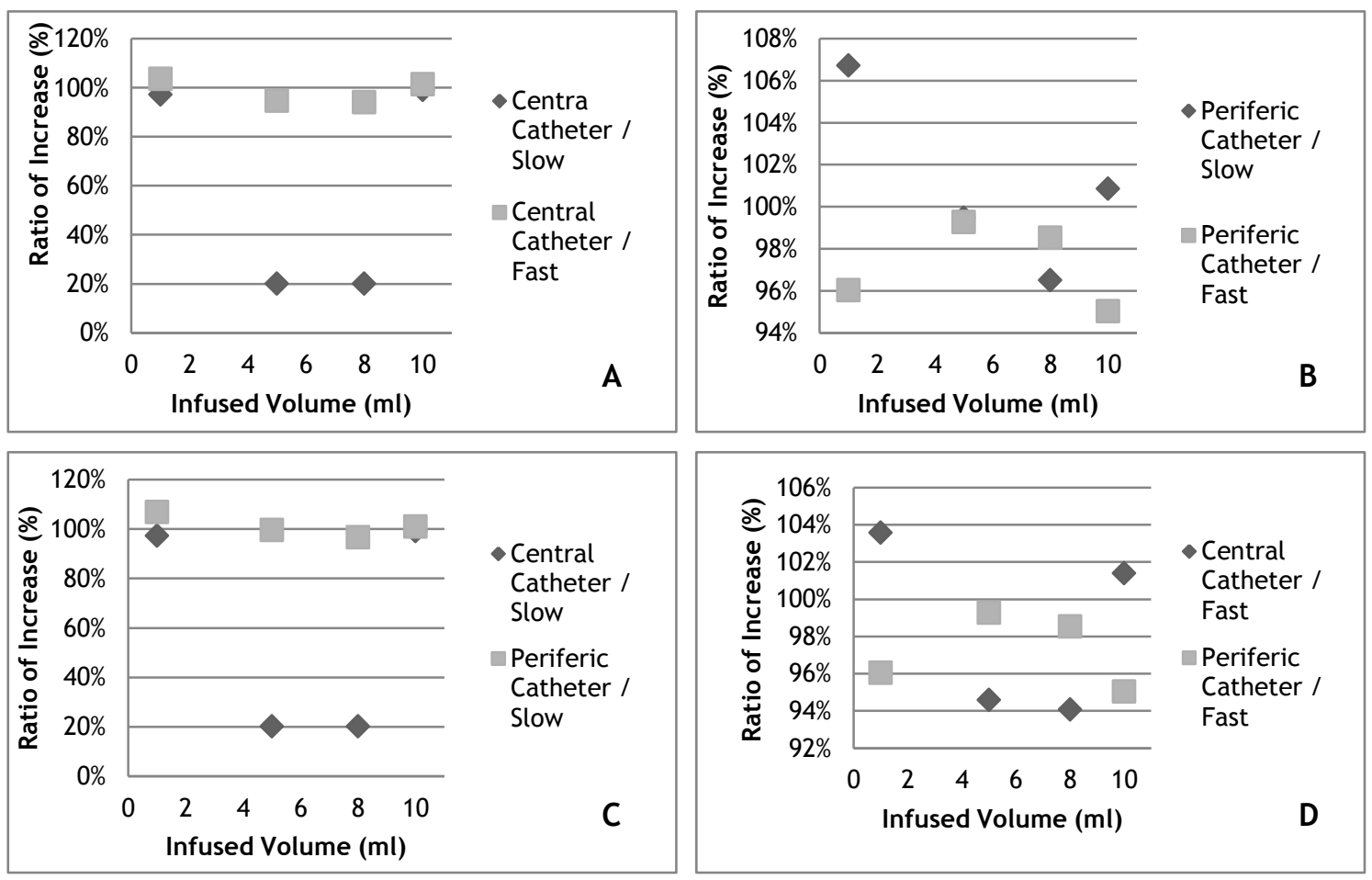

Figure 21 - Relation between the infusion volume and the ratio of increase (\%) of f50 for A) slow and fast velocities of saline infusion via central catheter; B) slow and fast velocities of saline infusion via periferic catheter; C) slow infusion of saline via central and periferic catheter; D) fast infusion of saline via central and periferic catheter.

Figures 21C) and 21D) shows that infusion given by central catheter via are less detectable than for peripheric via.

However, all ratios of increase values are too close from the baseline values (near 100\%) or below this limit what means that it is more difficult to detect changes in Doppler sound by evaluating the frequency relative to $50 \%$ of the Welch periodogram power. This may happen because when it is evaluated, important characteristics in higher frequency bands may be disregarded, mainly when turbulence episodes occur, since the power spectral density is shifted for higher frequencies. 
As Figure 22 shows, also the ratio of increase of $\mathrm{fm}$ relative to its basal values for different rates of infusion and administration catheters was observed.
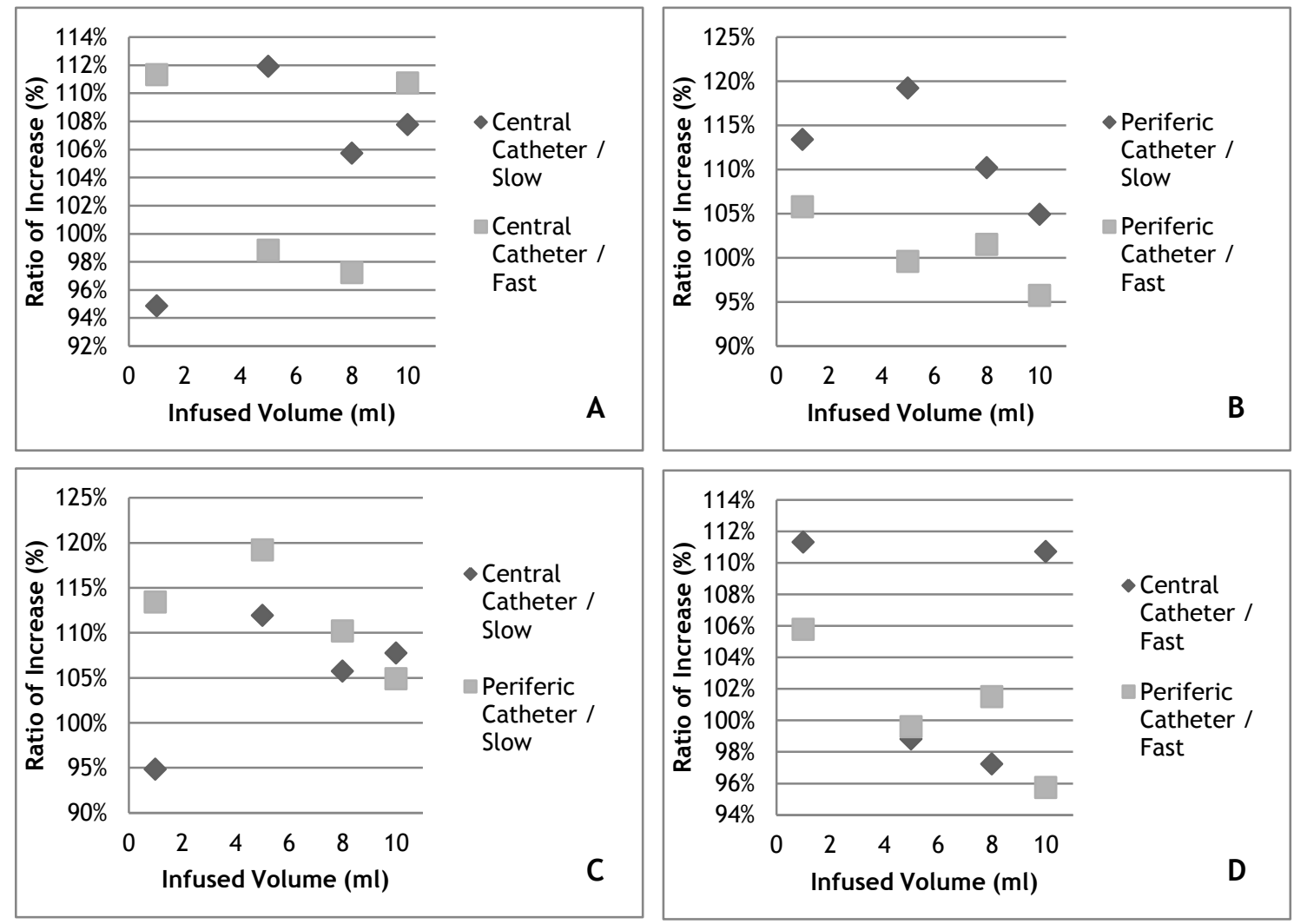

Figure 22 - Relation between the infusion volume and the rate of increase (\%) of fm for A) slow and fast velocities of saline infusion via central catheter; B) slow and fast velocities of saline infusion via periferic catheter; C) slow infusion of saline via central and periferic catheter; D) fast infusion of saline via central and periferic catheter.

Figure 22A) and 22B) shows that slow infusions leads to higher ratio of increase of $\mathrm{fm}$ relative to baseline values. However, $\mathrm{fm}$ is a feature that has too much error associated because of noise interference.

The same error influences the results on Figures 22C) and 22D). As can be seen, the infusions of saline administered by periferic catheter influence the episodes of turbulence more than the central catheter, what is not in consonance with the rational that episodes of turbulence are more evident with infusions via central catheter.

Entropy was another feature studied as referred above. Figure 23 shows the results obtained for this feature for different infusion volumes, for two rates and distinct catheters of administration. 

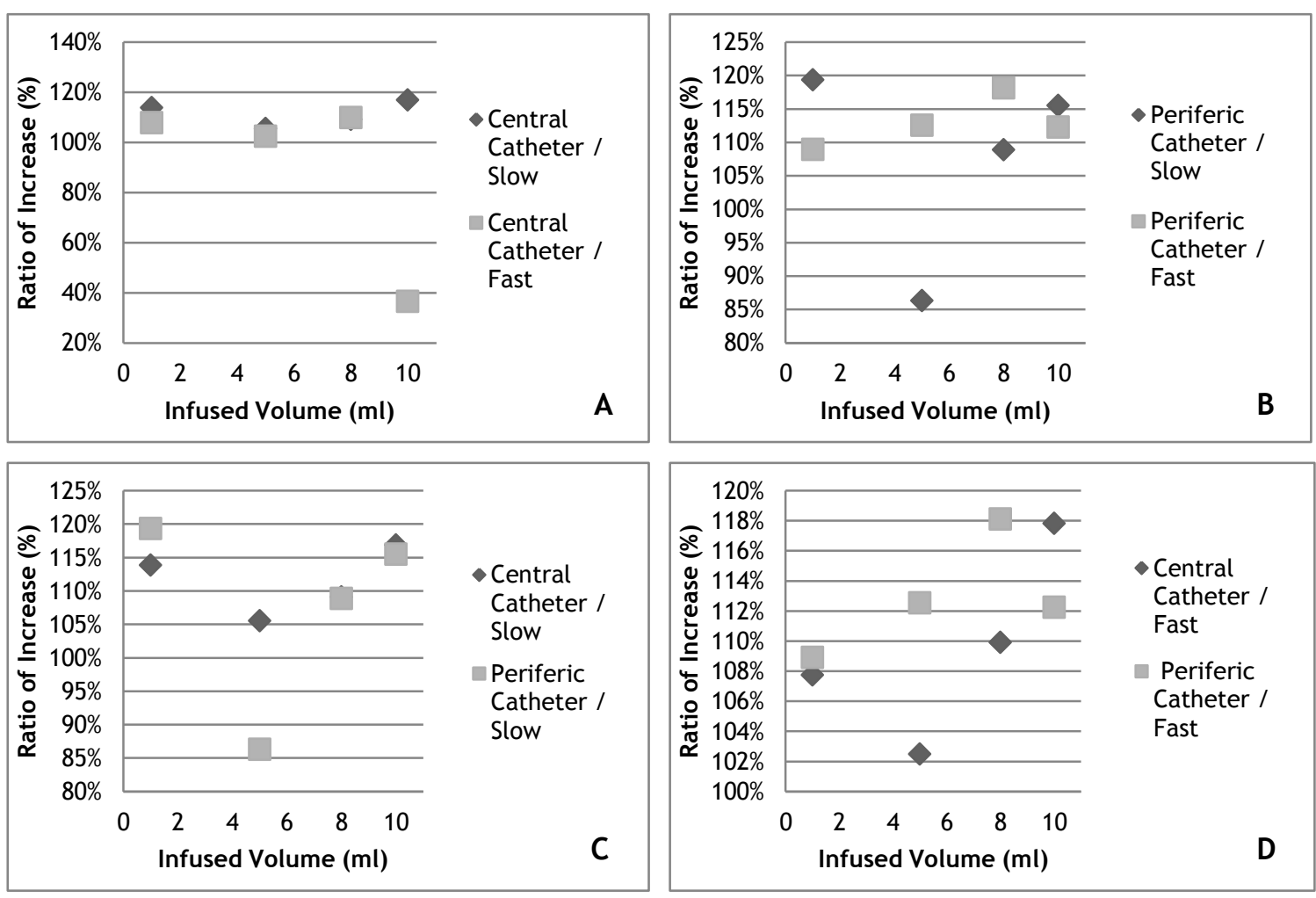

Figure 23 - Relation between the infusion volume and the rate of increase (\%) of E for A) slow and fast velocities of saline infusion via central catheter; B) slow and fast velocities of saline infusion via periferic catheter; C) slow infusion of saline via central and periferic catheter; D) fast infusion of saline via central and periferic catheter.

Figure 23A) and 23B) shows that there is a positive trend of the ratio of increase with higher infusion volumes. Also the infusions with higher rates tend to cause more turbulence in Doppler sound.

Also the rational that the turbulence is more easily detectable for central catheter, no matter the velocity that the infusions are given, is not demonstrated in figures 23C) and 23D) since the turbulence detection is equivalent for both catheters.

Another important observation is that this feature shows to be the more effective and consistent to detect episodes of turbulence once almost all values are superior to baseline values (ratio of increase superior to 100\%) and there are a linear relation between the rate of increase and the volumes administered: the higher is the infusion volume, the higher is the ratio of increase.

The last feature evaluated was the freqwav, as Figure 24 shows. 

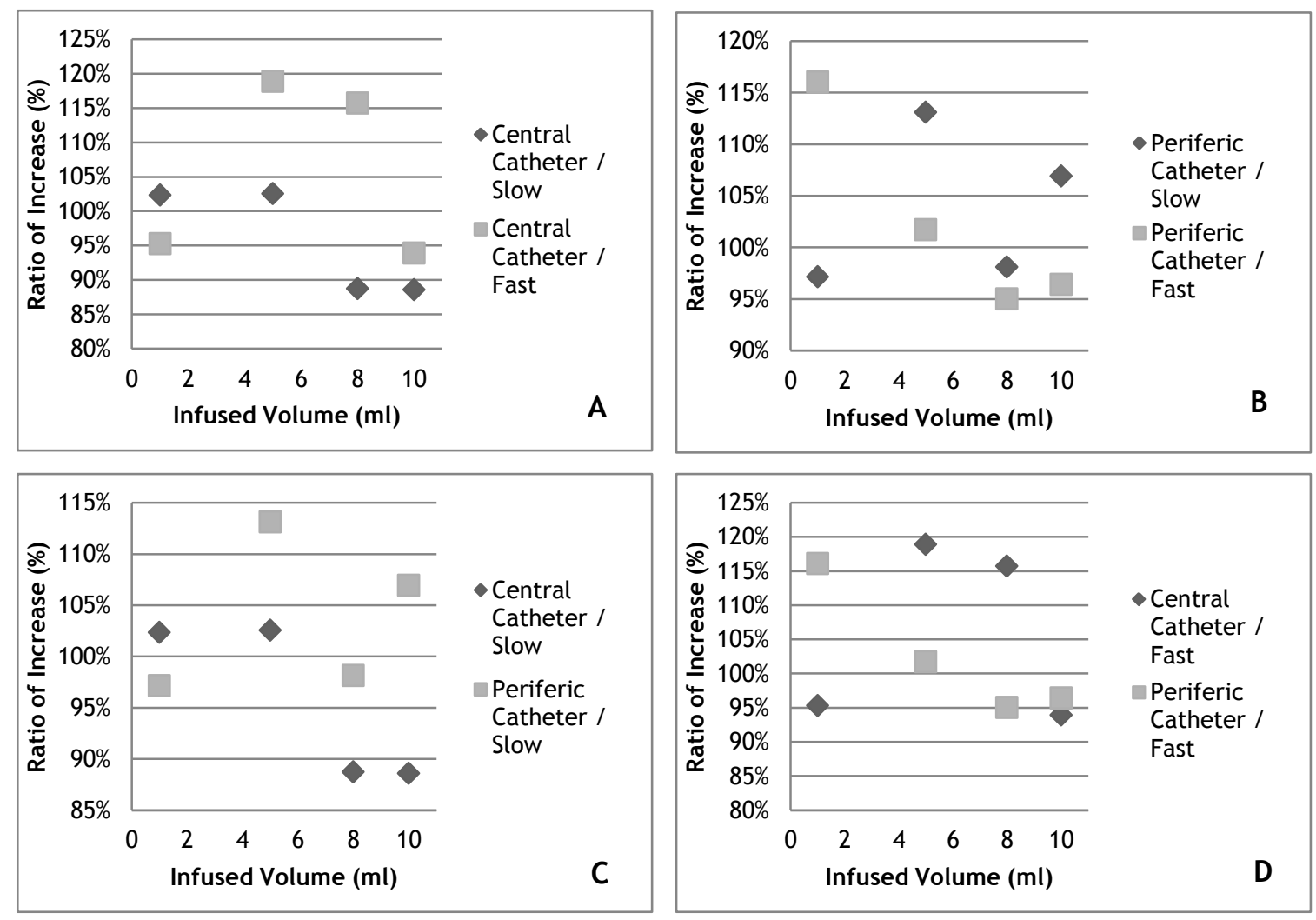

Figure 24 - Relation between the infusion volume and the rate of increase (\%) of freqwav for A) slow and fast velocities of saline infusion via central catheter; B) slow and fast velocities of saline infusion via periferic catheter; C) slow infusion of saline via central and periferic catheter; D) fast infusion of saline via central and periferic catheter.

Figure 24A) shows the evidence that infusions with higher rate are more easily detectable in terms of turbulence for central catheter. However for periferic catheter (figure 24B)), the opposite occurs which allows to conclude that this feature is less robust for detect changes in Doppler sound, also because most of the injection values are to close from the baseline value.

The results of figure $24 \mathrm{C}$ ) are inconclusive once rate of increase is in some cases higher then basal value and in the others, lowest. Figure 24D) demonstrates that only half of the infusions are detectable, being the fast infusions given by central catheter, which causes more detectable turbulence episodes.

In general the higher variability of the results is due to the few acquisitions used in this study. The patients enrolled in this study needed to fulfill the study requirements which limited the number of patients (more details in appendix VI). However, it is visible that the turbulence episodes are more evident with the increase of volume infusions and more easily detectable when the infusions are given via central catheter. Although, all features show that from a given volume $(8 \mathrm{ml}$ approximately), the results tend to stabilized near one value. This could be empirically explained because there is a ceil volume from which the turbulence is maximum. So, even if the volumes administered are increased, the changes in DHS would only depend on the limit of infusion administration rate. 
Fm feature did not correlate well to saline injections since this feature is more influenced by noise than the remaining features. On the other hand, E shows to be the feature with best results because almost all values corresponding to the infusions are higher than the basal value, which mean that this feature detected almost all sound interferences caused by the entry of saline infusion via central or peripheric catheters. Nevertheless, is not possible to say that this is the best feature to detect turbulent Doppler sound changes due to the low number of patients enrolled in this study.

\subsection{GUI}

Figure 25 presents the implemented interface and respective functions.

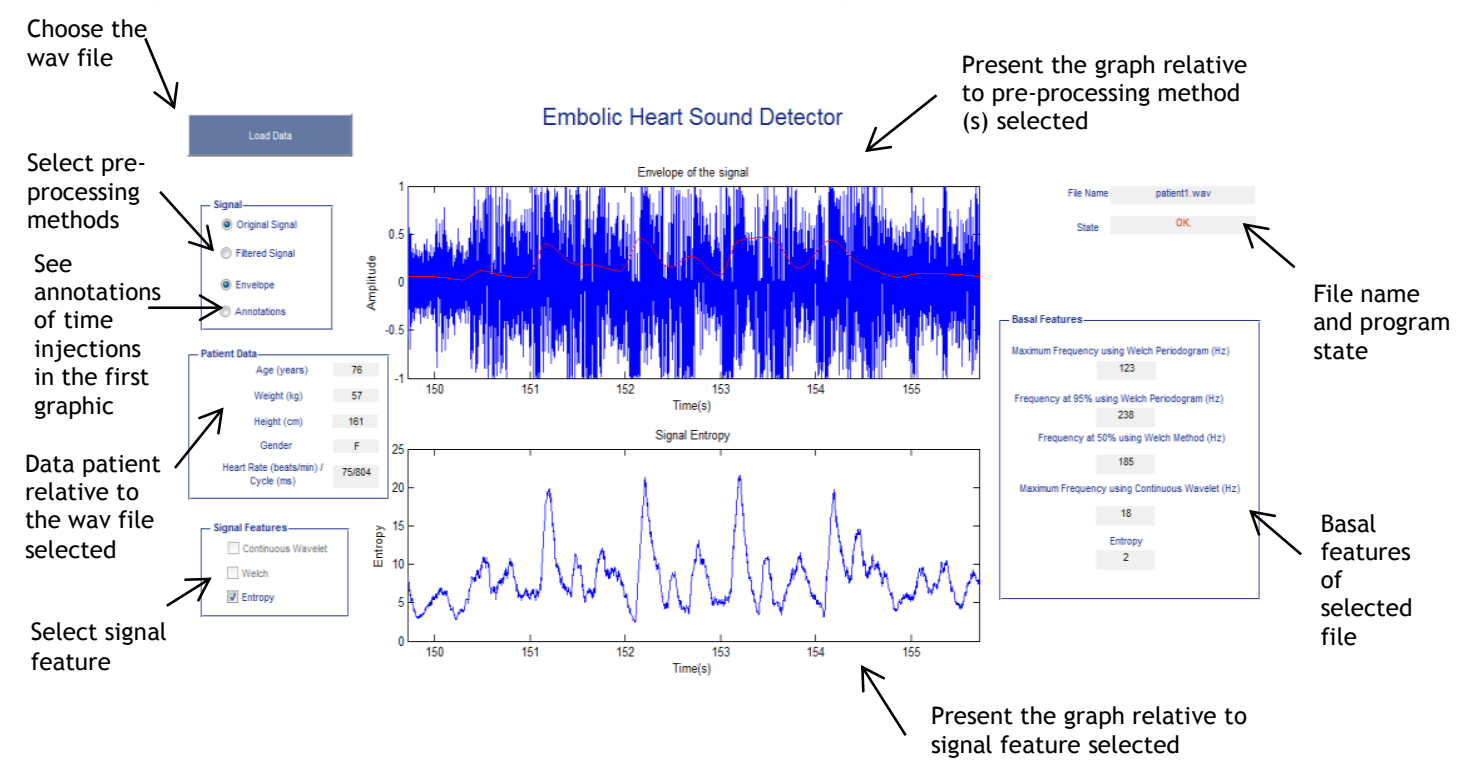

Figure 25 - Graphical Interface created and respective functions.

The creation of an interface was useful to help the user to understand how different approaches affect the signal (like filtering or envelope) and to see the features extracted and correlate them with the original signal. The main result of this interface was to have a database of Doppler sounds standardized, with annotations of different volumes and rate of saline injections and the behavior of different features for each signal as well as the data of each patient. This tool may be in the future adapted for on-line analysis of the DHS.

\subsection{Summary}

This chapter presented a discussion of the signal pre-processing methods as well as the results obtained after the evaluation of the extracted features. Also the created graphical interface and its functions were demonstrated.

The pre-processing techniques allowed having more clean homogeneous signals, with welldefined envelopes useful for posterior features extraction. 
The relation between the features and different characteristics like volumes and rates of infusion and catheters of administration, permitted to study the robustness of the features and infer about the characteristics that more contribute for changes in DHS: 


\section{Chapter 6}

\section{Conclusion and Future Work}

VAE is a serious problem that consists in accumulation of air bubbles on the right side of the heart. This event causes many health problems if not detected in time, even leading to the death of the patient.

Knowing how VAE occurs, and the physiology of the most affected areas (namely the heart), is important to understand how to prevent this event, and how to actuate when it occurs.

Many studies support the use of precordial Doppler as the less invasive and sensitive method for VAE detection. Nonetheless, it is difficult to detect changes in the Doppler sound when there is entrainment of small volumes of air in the heart, or due to the noise associated to the clinical environment. So, it turns difficult to detect VAE events every time that they occur, demanding constant attention from the anesthesiologist to the DHS.

There are few studies that try to improve the detection of VAE with precordial Doppler. These are with limited application, since they were designed to mimic VAE episodes in pigs or dogs.

In order to improve the detection of VAE episodes in humans, using the precordial Doppler, we designed the first study in human subjects, to our knowledge, for the signal processing of the DHS. This allowed acquiring some knowledge in the neuroanesthesiology area, and of the procedures for a clinical study design and accomplishment.

Mimicking VAE episodes by infusion of saline was the best way encountered to generate turbulence events in the heart. Also, the use of different infusion volumes, and catheters for administration, allowed the understanding of the impact of these conditions on the detection of EHS.

We propose a new methodology for the signal processing of the DHS. Pre-processing of the signal to eliminate out of band noise and normalization was implemented; a new method for signal envelope retrieval, and heart rate estimation, based on a Savitzky-Golay smoothed DHS was applied with success to DHS segmentation; finally, detected DHS events were analyzed for each patient, with several time-frequency features extraction for analysis. 
Five features were proposed in this study, and evaluated in response to saline injections. We observed a high variability in the results because the number of patients was low. This is a limitation of our study, since it was not possible to discern the feature that better detects changes in DHS in response to turbulence events. Nonetheless, we observed that the feature with best results was the entropy, once almost all saline infusions caused changes in Doppler sound detectable with this feature, when compared with the baseline DHS. The feature with worst results was Welch periodogram maximum frequency since almost no changes were observed when a turbulence episode occurred.

In a general way, it is possible to conclude that higher volumes of infusions turns the changes in the Doppler sound more evident and detectable when using these features. Also the detection of turbulence is more evident when the infusions of saline are administered by central catheter, probably because the infusion enters directly in the heart, where the Doppler probe is placed (externally). The construction of a GUI allowed the creation of a database with annotations, and off-line analysis of the behavior of the different features for the different DHS acquisitions.

As future work, it will be important to use the GUI to acquire Doppler heart sound and study the proposed features on-line. To do this, the number of acquisitions should be increased, improving the database of DHS, reducing the variability of the results, and assessing which feature or combination of features allow a better discrimination of turbulent DHS.

Another important step will be to acquire Doppler heart sound when VAE events occur, study these cases and correlate them with the results obtained in the turbulence induced by saline injections. This way, it will be possible to establish a threshold for each feature, test them when VAE events occur and assess which feature detects more Doppler heart changes. This information may be used to build an advisory system for the anesthesiologist, alerting in case of possible VAE, and decreasing the time between the detection of a VAE episode and clinical action. 


\section{References}

[1] Law, A., Gulati, A., \& Bhalla, A. (2012). Air in the heart: what should one do? American Journal of Emergency Medicine, 1659e1-1659e3.

[2] Albin, M. S. (2011). Venous Air Embolism. Anesthesiology, 626-629.

[3] Palmon, S. C., Moore, L. E., Lundberg, J., \& Toung, T. (1997). Venous Air Embolism: A Review. Jornal of Clinical Anesthesia, 251-257.

[4] Mirski, M. A., Lele, A. V., Fitzsimmons, L., \& Toung, T. J. (2007, January). Diagnosis and Treatment of Vascular Air Embolism. Anesthesiology, 106, 164-177.

[5] Sigel, B. (1998) A Brief History of Doppler Ultrasound in the Diagnosis of Peripheral Vascular Disease Ultrasound in Medicine \& Biology, 24, 169-176

[6] Seeley, R., Stephens, T., Tate, P., (2008) Anatomy and Physiology, Mc Graw Hill, $8^{\text {th }}$ Edition, 679-681

[7] Guyton, A., Hall, J., (2006) Textbook of Medical Physiology, Elsevier Saunders, $11^{\text {th }}$ Edition, 103-109

[8] Vesely, T. M. (2001, November). Air Embolism during Insertion of Central Venous Catheters. Journal Vasv Interv Radiol, 12, 1291-1295.

[9] Chan, F. H., Chan, B. C., \& et al. (1998). Volume Estimation by Wavelet Transform of Doppler Heart Sound During Venous Air Embolism in Dogs. Proceedings of the 20th Annual International Conference of the IEEE Engineering in Medicine and Biology Society, 20, 14631466.

[10] McQueen, K., \& Shedd, S. (1998, March). Neuroanesthesiology. Operative Techniques in Neurosurgery, 1, 14-22.

[11] Gan, T., Glass, P. et al. (1997). Bispectral Index Monitoring Allows Faster Emergence and Improved Recovery from Propofol, Alfentanil, and Nitrous Oxide Anesthesia. Anesthesiology, 808-815.

[12] Avidan, M., Zhang, L. et al. (2008). Anesthesia Awareness and the Bispectral Index. The New England Jornal of Medicine, 358, 1097-1108.

[13] Eikaas, H., \& Raeder, J. (2009). Total intravenous anaesthesia techniques for ambulatory surgery Ambulatory Anesthesia 725-729

[14] Raleigh, N. (2004) American Board of Anesthesiology: Booklet of Information, American Board of Anesthesiology 
[15] Muzzi, D. A., Losasso, T. J., Black, S., \& Nishimura, R. (1990). Comparison of a Transesophageal and Precordial Ultrasonic Doppler Sensor in the Detection of Venous Air Embolism. Anesthesiology, 103-104.

[16] Chan, B. C., Chan, F. H., \& et al. (1997, April). Fast Detection of Venous Air Embolism in Doppler Heart Sound Using the Wavelet Transform. IEEE Transactions on Biomedical Engineering, 44, 237-246.

[17] Schubert, A., Deogaonkar, A., \& Drummond, J. C. (2006). Precordial Doppler Probe Placement for Optimal Detection of Venous Air Embolism During Craniotomy. Neurosurgical Anesthesia, 1543-1547.

[18] Chan, F. H., Chan, B. C., \& et al. (1996). Detection and Quatification of Venous Air Embolism by Wavelet Analysis of Doppler Heart Sound. IEEE Engineering in Medicine and Biology Society, 1019-1020.

[19] Michenfelder, J. D., Miller, R. H., \& Gronert, G. A. (1972, February). Evaluation of an Ultrasonic Device (Doppler) for the Diagnosis of Venous Air Embolism. Anesthesiology, 36, 164-167.

[20] Lui, P.,Chan, B., Chan, F et al (1998) Wavelet Analysis of Embolic Heart Sound Detected by Precordial Doppler Ultrasound During Continuous Venous Air Embolism in Dogs. Neurosurgical Anesthesia, 86, 325-331

[21] Lui, P., Lin, Y., \& et al. (1993). Spectral Characteristics of Embolic Heart Sounds detected by Precordial Doppler Ultrasound during Venous Air Embolism in Dogs. Br. J. Anesthesia, 71, 689-695.

[22] Mo, L., Yun, L., \& Cobbold, R. (1988). Comparison of Four Digital Maximum Frequency Estimators for Doppler Ultrasound. Ultrasound Med., 355-363.

[23] Oppenheim, A., \& Schafer, R. (1989). Discrete-Time Signal Processing. Englewood Cliffs: Prentice - Hall.

[24] Chan, B. et al. (1997). A Real-Tome Monitor using Wavelet Analysis of the Doppler Heart Sound for the Detection of Venous Air Embolism IEEE International Symposium of Circuits and Systems, 189-192.

$$
\text { Normalization, }
$$

Matlab.

Available

in http://www.mathworks.com/help/simbio/ref/normalization.html. Acceded at June, $9^{\text {th }}$ of 2013

[26] Savitzky, A.; Golay, M.J.E. (1964). Smoothing and Differentiation of Data by Simplified Least Squares Procedures. Analytical Chemistry 36 (8), 1627-1639.

[27] Quan, Q., Cai, K. (2012) Time-domain analysis of the Savitzky-Golay Filters. Digital Signal Processing, 22, 238-245

[28] Damelin, S.; Miller, W. (2011) The Mathematics of Signal Processing, Cambridge University 
[29] Guest, P.G. (1961). Chapter 7, Estimation of Polynomial Coefficients, Numerical Methods of Curve Fitting, Cambridge University Press.

[30] Continuous Wavelet Transform , Matlab. Available in http://www.mathworks.com/help/wavelet/gs/continuous-wavelet-transform.html. Acceded at June, $11^{\text {th }}$ of 2013

[31] Tutorial Demos of Continuous and Discrete Wavelet Analysis, Matlab. Available in http://www.mathworks.com/help/wavelet/examples/continuous-and-discrete-waveletanalysis.html?prodcode=WA\&language=en. Acceded at June, $9^{\text {th }}$ of 2013

[32] Albin, M.; Venous Air Embolism: A Warning Not to Be Complacent - We Should Listen to the Drumbeat of History (2011), Anesthesiology, v115, №3: 626-629

[33] Schnider, T. et al; The Influence of Method of Administration and Covariates on the Pharmacokinetics of Propofol in Adult Volunteers (1998), Anesthesiology, v88: 1170-1182

[34] F. Roberts, et al. (1988) Induction and Maintenance of Propofol Anesthesia, Anaesthesia, Vol. 43 (Supp), 14-17

[35]Castro, A. et al. (2008) Eur J Anaesthesia, Vol. 25, Supp. 44, 150 


\section{APPENDIX I}

\section{Venous Air Embolism Management}

Following VAE detection the anesthesiologists need to institute several reversion measures, that following will be described in detail.

\section{Institute High - Flow Oxygen}

Once VAE is recognized, the patient should be placed on $100 \% \mathrm{O}_{2}$ and $\mathrm{N}_{2} \mathrm{O}$ should be discontinued. This is important to avoid the rapidly diffusion of $\mathrm{N}_{2} \mathrm{O}$ into trapped air bubbles which dramatically increase the size of the embolus [3, 4, 8]. Other therapeutic but rare solution is the placing of the patient in a hyperbaric chamber [1].

\section{Prevention of Further Air Entrainment}

When VAE is detected, some useful decisions to prevent the air entrainment can be done. One is flood the field with saline [3, 4].

Manual application of jugular compression would also impeding cerebral venous return and increasing CVP to provoke bleeding in wound edges. This bleeding could help the surgical team to find open veins, a possible source of air entry. Other advantage of this compression is the limitation of air entry into the chest and right atrium [3].

Other way to improve forward blood flow is to force air out of the pulmonary outflow tract into the smaller pulmonary vessels by initiation of cardiopulmonary resuscitation with defibrillation and chest compressions [4].

\section{Aspiration of Air from the Right Atrium}

This method will be used in this work whenever a VAE episode is detected. The aspiration of air will be done using a right atrial catheter (RAC) positioned near the right atrial vena cava junction as can be seen in Figure 24. Yet this medical procedure only retrieves approximately $50 \%$ of the air entrained [3]. Nevertheless, the volume extracted may be sufficient to prevent a fatal outcome. The catheter will have multi orifices because this is 
more effective than a single orifice catheter. Placement can be confirmed by using an ECG lead attached to the catheter [4].

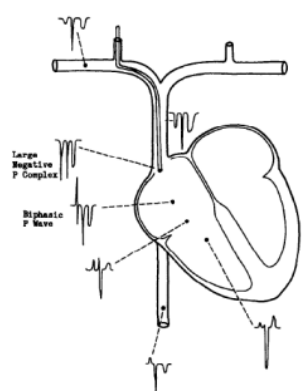

Figure 26. - The right atrial catheter positioned at the correct location to aspirate air. Electrocardiographic complexes at various intracardiac locations [3]. 


\section{APPENDIX II}

\section{Accepted Abstract to SNACC}

A new scheme for manual infusion of propofol, allowing individualization of doses required for anesthesia induction and adequacy of the initial maintenance rate

Introduction and Objectives: Intravenous anesthesia with propofol can be done with TCI or manual infusion. Robert's scheme has been used for induction and maintenance of TIVA with propofol [34]. The goal of our study was to develop a new scheme to be used on manual infusions, allowing individualization of a patient's requirement for propofol induction as well as the achievement of an adequate steady state concentration for maintenance.

Methods: 11 patients $69 \pm 18 \mathrm{~kg}, 167 \pm 11 \mathrm{~cm}$ and $50 \pm 16$ years, received anesthesia induced with $1 \%$ propofol at an infusion of $3,3 \mathrm{ml} / \mathrm{kg} / \mathrm{h}$. A Fresenius Base Primea pump was used, featuring $\mathrm{TCl}$ and set to $\mathrm{TCl}$-View mode. After LOC the infusion was stopped, the predicted effect-site concentration (Ce) of propofol, according to Schnider's Pk model, was noted, and the pump was switched to $\mathrm{TCl}$ mode with a Ce target calculated by a previously published formula [35]. Propofol infusion continued and data were recorded using Rugloop software every 5 seconds. Of-line analysis was performed, using propofol infused volumes and time during which the infusion stopped after LOC. Propofol doses, weight, age and height of the patients were used to develop a scheme to be used manually, to achieve, after LOC, an infusion rate resulting in calculated concentrations similar to those obtained in the patients. Ce's were simulated using the new proposed scheme and compared with the calculations obtained by applying Roberts' scheme to the data from our patients. Mean errors were used for comparison between the concentrations achieved by each scheme.

Results: The new proposed scheme consists on a slow induction with propofol at $3.3 / \mathrm{ml} / \mathrm{kg} / \mathrm{h}$, followed by an interruption of 170 s (since no relation was found between the interruption time and induction dose) and restart of the propofol infusion using the infusion rate estimated by the equation presented in figure 1 that correlates the total volume of infusion and the final infusion rate. 


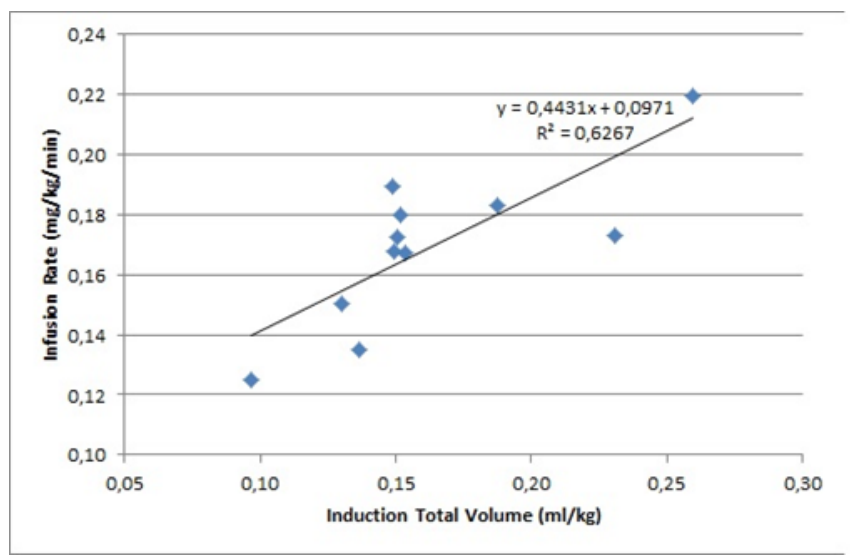

Figure 27 - Representation of the induction total volume $(\mathrm{ml} / \mathrm{kg})$ and the final infusion rate $(\mathrm{mg} / \mathrm{kg} / \mathrm{min})$, and corresponding linear regression.

The real and simulated Ce's are presented in Table 1, with respective mean error. The proposed scheme presents a small error when compared to the real Ce's $(0.21 \pm 0.09)$.

Table 4 - Mean and standard deviation of variables for each approach. Ce's for the patient 1, 4 and 10 were not recorded once all the time of anesthesia induction was minor than the chosen $(5$ minutes after de 2nd bolus).

\begin{tabular}{|c|c|c|c|c|c|c|c|c|c|}
\hline & \multicolumn{2}{|c|}{ Observed Values } & \multirow[b]{2}{*}{\begin{tabular}{|c|} 
Final Infusion \\
Rate $(\mathrm{ml} / \mathrm{h})$
\end{tabular}} & \multirow[b]{2}{*}{$\begin{array}{l}\text { Real Final } \\
\text { Ce }(\mu \mathrm{g} / \mathrm{ml})\end{array}$} & \multicolumn{2}{|c|}{ Proposed Scheme } & \multirow[b]{2}{*}{$\begin{array}{c}\text { Ce Error } \\
\text { (estimated } \\
\text { vs real) } \\
(\mu \mathrm{g} / \mathrm{ml})\end{array}$} & \multicolumn{2}{|c|}{ Roberts Scheme } \\
\hline & $\begin{array}{c}\text { Total } \\
\text { Induction } \\
\text { Volume: Vt } \\
\text { (ml/kg) }\end{array}$ & \begin{tabular}{|c|} 
Infusion \\
Interruption (s)
\end{tabular} & & & $\begin{array}{c}\text { Final Infusion } \\
\text { Rate (ml/h) }\end{array}$ & $\begin{array}{c}\text { Estmated } \\
\text { Final Ce } \\
(\mu \mathrm{g} / \mathrm{ml})\end{array}$ & & $\begin{array}{c}\text { Estimated } \\
\text { Final Ce } \\
(\mu \mathrm{g} / \mathrm{ml})\end{array}$ & $\begin{array}{c}\text { Ce Error } \\
\text { (estimated vs } \\
\text { real) }(\mu \mathrm{g} / \mathrm{ml})\end{array}$ \\
\hline Mean & 0,16 & 170 & 68,7 & 3,33 & 69,5 & 3,25 & 0,21 & 2,94 & 0,46 \\
\hline $\begin{array}{l}\text { Standard } \\
\text { Deviation }\end{array}$ & 0,04 & 23,6 & 11,3 & 0,45 & 14,1 & 0,50 & 0,09 & 0,40 & 0,35 \\
\hline
\end{tabular}

Discussion and Conclusions: We proposed a new scheme for manual infusion of propofol that reproduces the Ce's observed in a TCl induction. This allows a tailored induction, based on the induction dose observed for the individual patient. The error found between real and simulate Ce's validates the potential of this new scheme to maintain a patient stable during periods of 10 to 15 minutes counting from the beginning of the induction. 


\section{APPENDIX III}

\section{Intraoperative Anaesthetic Management}

The goals of the anesthetic maintenance are to provide hemodynamic stability throughout the surgical procedure and to respond to physiological changes that may occur or are required. Some changes include hypertension, hyperventilation, and the need for cerebral protection [10].

\section{Patient Positioning}

Some positions like supine, prone, lateral, park bench or sitting are used to facilitate surgical access.

The patients studied in this work will be always evaluated in supine position, once this present many advantages like good hemodynamic stability, reduction of intracranial pressure (ICP), ease of patient padding, and good patient access during the procedure [2, 10]. However, some useful considerations must be attended. In the prone position bleeding can obscure the surgical field [2].To overtake this, head-up tilt is used to reduce hemorrhages, but this increases the risk of air embolism (VAE). For this reason and besides de advantages of the sitting condition (g.e.: improved surgical exposure or good access to the endotracheal tube and extremities), it would not be applied this position [10].

\section{Control of Intracranial Pressure (ICP) and Hypertension}

Elevated ICP is problematic during neurosurgeries and can be treated with hyperventilation and head elevation. The use of diuretic agents like matinol is often used to reduce ICP.

Hypertension may be treated with beta blockade (esmolol), vasodilatation (sodium nitroprusside), or a combination of the two. Nevertheless, this is a necessary condition during neurosurgeries, to ensure adequate cerebral perfusion or when cerebral artery vasospasm occurs [10]. 
Controlled Hypotension, Hyperventilation, Cerebral Protection and Administration of Fluids

The control of hypotension is an important request during intracranial surgeries and sodium nitroprusside (SNP) is a short-acting agent used many times. Also electroencephalogram (EEG) monitoring must be used during these episodes. Other alternative is not to lower systolic arterial pressure by more than $50 \mathrm{~mm} \mathrm{Hg}$ below the patient's normal systolic arterial pressure.

Many neurosurgeries require hyperventilation to control elevated ICP or limit retraction of brain tissue.

Other concern is to protect the brain from the effects of ischemia. To make this, is used barbiturate and is induced hypothermia to reduce the cerebral metabolic rate, thereby increasing the length of time that brain can tolerate ischemia.

The fluid maintenance requirements are based on the patient's body weight. Thereby fluid deficits and losses are replaced, and cardiovascular performance is held. Normal saline is routinely chosen to maintain an adequate circulating intravascular volume [10]. 


\section{APPENDIX IV}

\section{Venous Air Embolism Complications}

\section{Hemorrhage}

The results of intracranial hemorrhage are severe since rapid blood loss with hemodynamic consequences and difficulties in vascular control can occur. Also the access to the pathology is limited. To overcome this, the patient's blood pressure should be lowered to assist the neurosurgeon in regaining vascular control. If rapid control is not achieved, volume replacement should begin, initially with crystalloids or colloids and subsequently with blood if the hemorrhage continues [10].

\section{Cerebral Edema}

Preventing factors that contribute to cerebral edema is a standard goal of anesthesia during neurosurgeries [10]. By minimizing tissue retraction throughout proper patient positioning, it can be possible to achieve this goal. Once pharmacological agents like steroids and diuretics may improve cerebral edema, the management is done by optimization of ventilation and blood gases and maximization of venous drainage $[2,10]$. Also the administration of drugs like propofol or lidocaine could minimize $\mathrm{CMRO2}$, decreasing the probability of this problem occur [2]. 


\section{APPENDIX V}

\section{Venous Air Embolism Detection Methods}

\section{Transesophageal Echocardiography (TEE)}

TEE is the most sensitive monitoring device for VAE once it can detect as little as 0.02 $\mathrm{ml} / \mathrm{kg}$ of air administered by bolus injection. However, TEE is invasive, expensive, requires expertise and constant vigilance, and the risk of esophageal injury during prolonged use has limited its clinical use [3, 4].

A report by Himmelseher et al noted that the use of TEE as standard of practice represent only $38 \%$ of patients undergoing intracranial procedures, compared with the use of precordial Doppler ultrasound [4].

\section{Transcranial Doppler}

Contrast-enhanced transcranial Doppler is highly sensitive and has been used as a monitoring device for patients undergoing high-risk procedures. In comparison with TEE, contrast-enhanced transcranial Doppler has shown a sensitivity of $91.3 \%$, specificity of $93.8 \%$, and overall accuracy of $92.8 \%[4]$.

\section{Pulmonary Artery Catheter (PAC)}

PAC is a relatively insensitive device of air entrainment $(0,25 \mathrm{ml} / \mathrm{kg})$ inferior to the precordial Doppler and too invasive for patient undergoing neurosurgical procedures [4]. For this reasons, the placement of PAC should not be considered routine. In addition, there are more effective catheters for the aspiration of air (with multi-orifice) [3].

\section{ETN2 and ETCO2}

$\mathrm{ETN}_{2}$ is the most sensitive gas-sensing VAE detection method once it measure increases as low as $0.04 \%$. Beyond not all anesthetic monitors have the capability to measure ETN 2 , this method is not useful if nitrous oxide is used as a carrier gas [4].

The $\mathrm{ETCO}_{2}$ is the most convenient and practical monitor used in the operating room [3 4]. A little change of $2 \mathrm{mmHg} \mathrm{ETCO}_{2}$ can be indicative of VAE. The bigger disadvantage of this device is its non-specificity [4]. 


\section{Electrocardiographic Changes}

Alterations in the electrocardiogram are lower for VAE detection because changes are seen only with rapid entrainment of air, and generally reflect a severe cardiac status. Peaked $P$ waves are the first change seen on a 12-lead electrocardiogram in animal studies. However, in humans, ST-T changes are noted first, followed by supraventricular and ventricular tachyarrythmias [4]. 


\section{APPENDIX VI}

\section{Clinical Protocol}

DESENVOLVIMENTO DE UM SISTEMA PARA DETECÇÃO AUTOMÁTICA DE EMBOLIA GASOSA ATRAVÉS DE DOPPLER TRANS-TORÁCICO

\section{- Introdução e Objectivos}

A embolia gasosa é uma complicação que pode ocorrer durante procedimentos neurocirúrgicos [1]. Resulta da existência de gradientes de pressão entre o lado direito do coração e a zona de incisão. É mais frequente para a posição de sentado (incidência de 25\%) [32], mas pode ocorrer também nas posições supina ou lateral (incidência entre 15\% e 25\%).

Quando não é detectada a tempo, a embolia gasosa pode provocar graves problemas de saúde como cianose, AVC, obstrução do fluxo sanguíneo pulmonar ou colapso cardiovascular devido à acumulação de bolhas de ar, resultando na distensão do lado direito do coração [3, 32].

As alterações no som cardíaco são características de embolia gasosa e o anestesiologista tem um papel importante na sua detecção através do uso de uma sonda Doppler que permite a monitorização em tempo real do som cardíaco [5, 32]

Nos procedimentos cirúrgicos, nomeadamente cirurgias cerebrais, em que o risco de embolia gasosa é elevado, o doente é monitorizado com Doppler pré - cordial e é-lhe colocado um cateter central com vários orifícios na extremidade, o qual é colocado na entrada da aurícula direita de modo a permitir a aspiração de sangue com as bolhas de ar, no caso em que houver suspeita de entrada de ar na circulação, uma vez que estas bolhas se tendem a alojar na aurícula. Por norma o anestesiologista, uma vez colocado o cateter central na aurícula e o Doppler pré - cordial, procede a uma injeção rápida de soro fisiológico através do cateter central de modo a confirmar, através da alteração produzida no som do Doppler, o correcto posicionamento da sonda de Doppler.

Durante uma cirurgia, geralmente com duração de muitas horas, detectar uma embolia gasosa implica uma atenção contínua do anestesiologista. Uma vez que o anestesiologista precisa de focar a sua atenção noutras tarefas, a detecção de embolias gasosas pode ser afectada, principalmente por haver a possibilidade de ocorrerem falsos positivos. 
Assim, desenvolvemos um projecto cujo objectivo final será o desenvolvimento de um sistema que permita a análise contínua e automática do som do Doppler pré - cordial de modo a poder detectar precocemente, em doentes submetidos a procedimentos cirúrgicos com risco de embolia gasosa, a ocorrência de entrada de ar na circulação e avisar o anestesiologista e o cirurgião através de um alarme. Um objectivo paralelo é estudar a possível relação entre alterações no fluxo sanguíneo produzidas pela entrada de ar ou de soro na circulação e alterações na curva da pressão venosa central.

Numa primeira fase, a que corresponde o estudo que agora nos propomos realizar no Hospital de Santo António, pretendemos proceder à recolha do som obtido com um Doppler pré cordial, durante a anestesia e cirurgia de doentes sem risco de embolia gasosa, e utilizar a injecção endo - venosa de soro fisiológico para produzir alterações na característica do som do Doppler pré - cordial como fase inicial de desenvolvimento de um sistema automático de análise do som com vista à detecção de embolias gasosas.

Assim, o objectivo específico do estudo agora proposto é a aquisição contínua do som do Doppler pré - cordial e a análise da exequibilidade da detecção automática de possíveis alterações no som do Doppler pré - cordial, bem como a possível ocorrência de alterações produzidas pela injecção de soro sobre as curvas da pressão venosa central e da pressão intraarterial.

Em doentes cirúrgicos cujo procedimento implique a inserção de um cateter venoso central e de um cateter arterial, procederemos à colocação de um monitor de Doppler pré cordial e à injecção de pequenos volumes de soro fisiológico. Nesses casos será feita a aquisição contínua do som do Doppler e das ondas da pressão venosa central e arterial e registados os momentos da administração das injecções.

Período de colheita: 4-8 semanas

Número de casos: 6

\section{- Critérios de Selecção e Monitorização}

Serão estudados pacientes adultos, submetidos a procedimentos neurocirúrgicos e sujeitos a anestesia geral, com um estado físico de I a III na escala de ASA (Sociedade Americana de Anestesiologistas). Serão incluídos pacientes que conheçam os critérios de inclusão e que concordem em participar através da submissão do consentimento informado, obtido pelos anestesistas durante a visita pré-anestésica. A realização do estudo em doentes neurocirúrgicos deve-se apenas à existência no bloco operatório de neurocirurgia de um software de aquisição de dados e à frequência com que os doentes são monitorizados com cateter venoso central e arterial.

A técnica anestésica e a monitorização dos pacientes serão realizadas de acordo com os protocolos do Serviço de Anestesiologia do HSA-CHP, e os sinais fisiológicos do paciente serão gravados de forma contínua, usando o software Rugloop $\|^{\odot}$ de aquisição de dados. A sonda 
Doppler pré - cordial a utilizar é a existente no bloco operatório de neurocirurgia e é apresentada na figura 25 .

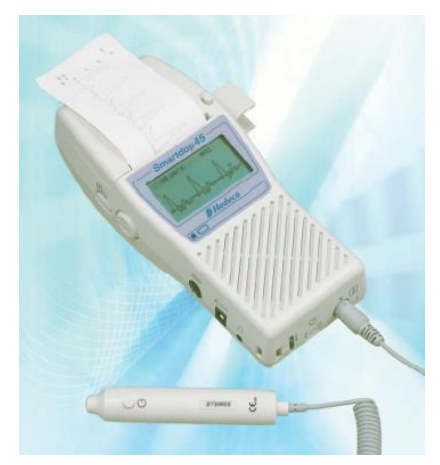

Figure 28 - Doppler pré - cordial da Hadeco, modelo Smartdop $45^{\circ}$.

Para cada paciente será criada uma pasta num computador, com o código que the foi atribuído onde serão registados os dados do paciente (sexo, idade, peso, altura e condição médica). Nestas pastas, serão ainda guardados dados recolhidos durante a cirurgia.

Todos os equipamentos e monitores necessários para o estudo fazem parte da monitorização de base para este tipo de cirurgias, pelo que não acarretam custos adicionais para o hospital. O software Rugloopll e um computador dedicado existente já no bloco operatório de neurocirurgia. 0 uso do monitor Doppler implica apenas o uso de um consumível que é o gel condutor, cujo preço, para a pequeníssima quantidade utilizada, nos parece desprezível. Os únicos custos gerados pelo estudo são os relativos a quatro seringas por doente (de 1, 5, 8 e $10 \mathrm{ml}$ ) e a menos de $500 \mathrm{ml}$ de soro fisiológico por doente.

\section{- Critérios de Exclusão}

Serão excluídos pacientes com:

$-I M C>30$;

- Arritmias cardíacas;

- Cirurgia com risco de embolia gasosa.

\section{- Indução anestésica}

Será de acordo com o critério clínico, sem qualquer restrição para o estudo.

\section{- Procedimento}

Serão administrados de forma randomizada 4 volumes distintos de soro fisiológico $(1 \mathrm{ml}$, $5 \mathrm{ml}, 8 \mathrm{ml}$ e $10 \mathrm{ml}$ ) por duas vias distintas: o cateter venoso periférico utilizado para a administração de fluidoterapia e o cateter venoso central. Cada conjunto de 4 injecções será administrado de forma manual em duas velocidades diferentes, uma com a maior velocidade possível e outra um pouco mais lenta. As administrações de soro serão realizadas pelo médico 
anestesista responsável pelo estudo com todo o cuidado para não proceder à injecção de qualquer bolha de ar. Deste modo, os pacientes receberão um total de 16 injecções de soro, com 3 minutos de intervalo entre cada injecção. A administração de todos os volumes de soro deverá ser realizada sempre pela mesma pessoa [17].

Serão adquiridas continuamente as ondas relativas ao som de Doppler; à pressão arterial, à pressão venosa central e à pletismografia. Serão incluídos doentes independentemente da posição em que sejam operados.

\section{- Tratamento dos dados e processamento de sinal}

Após a recolha das ondas relativas ao som de Doppler; à pressão arterial, à pressão venosa central e à pletismografia, deverá ser estudada qual a sua relação através de processamento off-line. Serão investigados os seguintes aspectos:

- Avaliar no som de Doppler quais as frequências características da entrada de soro na corrente sanguínea e quais os volumes/velocidades a que é possível detectar-se a entrada de soro através dessas características;

- Com base no ponto anterior, criar um algoritmo de detecção automática, a testar no som gravado obtido em cada um dos doentes estudados, para avaliar a eficácia com que detecta o momento das injecções de soro;

- Estudar possíveis alterações da pressão arterial e da pressão venosa central e tentar relacionar estes gradientes com a administração de soro a volumes e velocidades distintos;

- Verificar no som de Doppler os tempos a que são detectadas as frequências características da entrada de soro, e os tempos a que são detectadas as variações de pressão arterial e/ou venosa para estabelecimento de uma relação entre o som de Doppler e os dois tipos de pressão. 


\section{APPENDIX VII}

Table 5 - Mean of the five sound features' ratio evaluated, for each infusion via, velocity and volume. Mean_Mf95=mean of maximum frequency at $95 \%$ of Welch periodogram integral; Mean_Mf95=mean of maximum frequency at $50 \%$ of Welch periodogram integral; Mean_Mfm=mean of maximum of maximum frequency of Welch periodogram; Mean_ME=mean of maximum Entropy; Mean_Mfreqwav=mean of maximum of maximum frequency using the continuous wavelet.

\begin{tabular}{lccccc} 
& Mean_Mf95 & Mean_Mf50 & Mean_Mfm & Mean_ME & Mean_Mfreqwav \\
Infusion Via/Velocity/Volume & $(\%)$ & $(\%)$ & $(\%)$ & (\%) & (\%) \\
\hline \hline Central Catheter / Slow / 1ml & 105 & 97 & 95 & 114 & 102 \\
Central Catheter / Slow / 5ml & 99 & 99 & 112 & 106 & 103 \\
Central Catheter / Slow / 8ml & 105 & 96 & 106 & 109 & 89 \\
Central Catheter / Slow / 10ml & 101 & 102 & 108 & 117 & 89 \\
Central Catheter / Fast / 1ml & 99 & 104 & 111 & 108 & 95 \\
Central Catheter / Fast / 5ml & 102 & 95 & 99 & 102 & 119 \\
Central Catheter / Fast / 8ml & 103 & 94 & 97 & 110 & 116 \\
Central Catheter / Fast / 10ml & 104 & 101 & 111 & 118 & 94 \\
\hline Periferic Catheter / Slow / 1ml & 101 & 107 & 113 & 119 & 97 \\
Periferic Catheter / Slow / 5ml & 99 & 99 & 119 & 86 & 113 \\
Periferic Catheter / Slow / 8ml & 100 & 96 & 110 & 109 & 98 \\
Periferic Catheter / Slow / 10ml & 105 & 101 & 105 & 116 & 107 \\
Periferic Catheter / Fast / 1ml & 106 & 96 & 106 & 109 & 116 \\
Periferic Catheter / Fast / 5ml & 108 & 99 & 100 & 113 & 102 \\
Periferic Catheter / Fast / 8ml & 105 & 99 & 101 & 118 & 95 \\
Periferic Catheter / Fast / 10ml & 99 & 95 & 96 & 112 & 96 \\
\hline
\end{tabular}

